\title{
Entertainment, Culture, and Media Art
}

$\operatorname{AUTHOR}(\mathrm{S})$ :

Nakatsu, Ryohei; Tosa, Naoko; Rauterberg, Matthias; Xuan, Wang

\section{CITATION:}

Nakatsu, Ryohei ...[et al]. Entertainment, Culture, and Media Art. Handbook of Digital Games and Entertainment Technologies, Vol.1 2017: 725-776

\section{ISSUE DATE:}

2017

URL:

http://hdl.handle.net/2433/250758

\section{RIGHT:}

This is a post-peer-review, pre-copyedit version of an article published in 'Handbook of Digital Games and Entertainment Technologies, Volume I'. The final authenticated version is available on line at:

https://doi.org/10.1007/978-981-4560-50-4_16; The full-text file will be made open to the public on 10 August 2018 in accordance with publisher's 'Terms and Conditions for Self-Archiving'; This is not the published version. Please cite only the published version; この論文は出版社版でありません。引用の際には出版社版をご確認ご利用ください。 


\title{
Entertainment, Culture, and Media Art
}

\author{
Ryohei Nakatsu, Professor, National University of Singapore, Singapore \\ Naoko Tosa, Professor, Kyoto University, Japan \\ Matthias Rauterberg, Professor, Technical University of Eindhoven, The Netherland \\ Wang Xuan, Researcher, Rolls-Royce Singapore, Singapore
}

\begin{abstract}
This chapter is dedicated to explore the relationship between entertainment, culture, and media art. Firstly the positioning of entertainment will be described including historical point of view and also focusing recent digital entertainment technologies. It will be clarified that entertainment is closely related to the mental sustainability of human and therefore has a close relationship with culture and art. Then, based on this, further investigation will be carried out to explain how culture and technology could be combined together. Firstly the relationship between culture and technology will be discussed proposing the concept of "Cultural Computing." Then three typical research examples of Cultural Computing, "ALICE," "ZENetic Computer," and "Confucius Chat" will be described emphasizing how cultural issues could be treated using computer both in Western culture and Eastern culture. As art is the core part of culture, as a next step how art, especially new art called media art where technology plays an important role, can treat cultural issues is discussed. And, as an example, media art created by an Eastern media artist will be introduced as a good example of such media art treating cultural issues.
\end{abstract}

\section{Introduction}

Network, information, and media technologies are rapidly changing our society, including human relationship, lifestyle, and communication. Entertainment is the area where these new technologies have a strong influence (Nakatsu, 2005). One good example is games. Playing computer/video games, or in other word digital games, is a common daily activity for people, especially for young generation. In particular, smartphone-based casual games have become very popular in both U.S. and Asian countries (Juul, 2012). Another good example is communication. People communicate with their families and friends through e-mail, mobile phones, texting, Twitter, and other means. Until the 1980s, communication media such as telephones were mainly used for business communication. Today, however, communication extends beyond business conversations and has become a form of everyday entertainment. It looks that "Global 
Village" proposed by Marshall MacLuhan has been already realized (McLuhan M and Powers BR, 1992; McLuhan 2011).

There are many discussions on these phenomena, but most of them merely observe what is happening in society and report the fact that more people are spending more time enjoying these new forms of entertainment. Unfortunately, however, there has been little consideration regarding the basic reason why these new forms of entertainment have been accepted by people all over the world. One of the fundamental questions is what is the main role of entertainment in our society and everyday life (Nakatsu, 2010).

The thought that culture, especially art as a core part of culture, is an essential part of or life has been commonly accepted. As entertainment has generally been understood to mean digital games, however, the relationship between entertainment, culture, and art has little been considered and discussed. As various aspects of entertainment, especially from technological point of view, are discussed and described in other sections of this handbook, mainly in this section the focus will be put on the relationship between entertainment and art. And in this chapter, culture with its broad meaning including art as its core part will be discussed from a point of entertainment and technologies.

In this chapter, firstly the relationship between technology and culture will be discussed. As a first step the definition of culture will be clarified and then how culture could be treated by computer will be discussed. Based on this introductory discussion, a new concept called "Cultural Computing," which is a new research area trying to treat various cultural issues by computer, will be proposed. Then three typical examples of Cultural Computing will be described and discussed. One example, ALICE (Hu et al., 2008; Bartnek et al., 2008), was carried out in Western country and other two examples, ZENetic Computer (Tosa et al., 2005; Toa and Matsuoka, 2006) and Confucius Chat (Khoo et al., 2011; Wang et al., 2013), were carried out in Eastern countries. Therefore by comparing these three researches it would be interesting to notice the similarities and differences on how cultural issues are treated in West and East.

Secondly the relationship between art and culture focusing how technology would work to connect these two will be discussed. Recently new art called media art, where technology plays an important role, has become an important part of fine art. Although there was a tight relationship between culture and art in old days, recent media art has strongly been influenced by technologies, which make the expression form of art look more modern and cool. Therefore the relationship between culture and art has become not so apparent. As a first step the recent trend of media art will be briefly discussed. Then an example of media art where cultural issues are richly expressed by using technologies will be described (Tosa et al., 2013). 


\section{Entertainment}

\subsection{Are we accused of by enjoying entertainment?}

It has been commonly understood, especially by the advance of digital technologies, that entertainment generally means digital games such as video game, computer game, etc. In developed countries new types of entertainment have emerged, such as chat on mobile phones and games on game machines and PCs. People in those countries are tending to spend more and more time enjoying such forms of entertainment. Established entertainment industry is huge and includes the movie, game, sports, and other businesses. There have been significant concerns and complaints about this trend. The basic logic of such complaints is that compared with other human activities, such as education, business, industrial production, and so on, entertainment is not productive. In other words, the complaints suggest that entertainment is only a waste of time.

On the other hand at least one billon people currently face starvation all over the world. For these people it is crucial to obtain food for tomorrow or even today. This problem has been one of the most serious topics at global conferences and meetings such as World Economic Forum (Dutta and Mia, 2009).

An important question, however, is whether people who live in developed countries should be accused of by enjoying entertainment neglecting the situation in under-developing countries, Another question is why the demand and markets for such entertainment are so huge. The issue of whether entertainment is a waste of time clearly requires care.

\subsection{Origin of entertainment}

What is happening now is not a totally new phenomenon. In earlier times, human life was simple. Humans farmed or hunted to survive. When people were not occupied with these tasks, they entertained themselves by various means. In other words, we can say that food is strongly related to our physical sustainability, yet at the same time, we can point out that entertainment is related to our mental and spiritual sustainability.

Then the era of civilization began. People introduced various novel types of activities, such as art, business, learning and teaching, and religion. Because of these activities, entertainment came to be considered as a secondary activity in human life. Although entertainment remained a certain part of our everyday life, it has not been considered an essential part. Figure 2.1 illustrates these changes in our physical and mental sustainability (Nakatsu, 2009).

\subsection{Our life and entertainment}


Even now sometimes that fact that entertainment is an important part of our life becomes apparent. Consider passengers on an airplane. During a flight, most people sleep, eat, or entertain themselves by watching movies, reading novels, and so forth. Only a few people work during a flight. This means that in a simple situation, our lifestyle consists of three basic activities: sleeping, eating, and entertaining ourselves (Nakatsu, 2009).

What is happening now is, in one sense, an "entertainment renaissance." The introduction of new technologies, especially interactive technologies, into traditional forms of entertainment has totally renewed and strengthened those forms. People are again noticing the basic strength and meaning of entertainment and recognizing that it is a substantial part of their lives. This is a key point in trying to understand such substantial issues as the role of entertainment and the future direction of entertainment (Rauterberg, 2006).

\subsection{Entertainment, culture, and art}

As is indicated by Fig. 1, there is a tight connection between entertainment, culture, and art. Although more detailed discussion will be carried out later, culture is easily understood something that covers the whole diagram shown in Fig. 1. Also art is an essential core part of culture. As has been described before by the recent advances in IT, new types of entertainment such as various types of digital games, new communication forms, have appeared. This means that it is important at this point to reconsider the relationship between entertainment, culture and art. As has been understood, entertainment covers wide area of human everyday activities. Therefore by keeping in mind that entertainment has a tight relationship with culture and art, in the following chapters and sections of this paper it will be discussed how culture and art could be combined with technologies.

\section{Culture}

\subsection{Definition}

In many ways, computing has transformed the way people preserve and disseminate culture. Scientific methods have helped in various stages in the identification, preservation, authentication, and retrieval of cultural contents, not only in the form of digital representation and recreation of physical cultural assets as online repositories, but also creating new forms of interactions with them. Culture, as a general term, can be divided into two categories: tangible culture and intangible culture. The UNESCO World Heritage Center defines cultural heritage as "the legacy of physical artifacts and intangible attributes of a group or 
society that are inherited from past generations, maintained in the present and bestowed for the benefit of future generations" (Eriksen, 2001). In this section, we provide a review on how computing technology is used for these two types of culture.

\subsection{Tangible culture}

Tangible culture, or material culture as termed in social sciences, refers to culture that is tangible or touchable, such as sculptures, architectures, paintings, etc. Much of these tangible culture are considered worthy of preservation for the study and appreciation of human history and society. Computing methods have been utilized to help achieving this goal. One major research area is digital cultural heritage, which specifically concerns with digital recreations of historical sites or artifacts using $2 \mathrm{D}$ or $3 \mathrm{D}$ modeling techniques, or the management of such resources (Cameron and Kenderdine, 2007; Koller et al., 2009; Levoy et al., 2000). For example, Okada et al. used advanced analytic techniques to restore the historical scripts and illustrations to its original form (Okada, 2010), and the Virtual Kyoto project built geo-temporal referenced 3D models of the entire city of Kyoto (Nakaya et al. 2010). Some of the models built are accessible online as e-museums (Shiaw et al., 2004), where people can easily browse, retrieve and explore the tangible culture from a computer interface. Furthermore, interactive installations have been set up in physical museums, allowing easy access to the information in ways such as augmented reality (Choudary, 2009) and natural gestures (Alici et al. 2010), etc.

\subsection{Intangible culture}

Intangible culture, such as oral traditions, customs, ways of life, traditional craftsmanship, performing arts, theater, social practices etc., represents cultural identities and diversity of mankind, and is also an important part of culture. Modern computing and interaction techniques bring new possibilities for its preservation and promotion, allowing not only easier access and retrieval of these intangible cultural contents, but also participation and learning through a simulated or recreated experience.

\subsubsection{Archiving and retrieval of intangible cultural contents}

Like the work on tangible culture, many of existing work on intangible cultural contents focuses on archiving and browsing, where the content structuring and accessibility are the major concerns. For example, Mallik et al. (Mallic et al., 2011) created a repository that encoded domain knowledge with digitized records of Indian dance and music using an ontology-based approach. A browsing application is developed for semantically access the collection of Indian dance videos. Stavrakis (Stavrakis et al., 2012) created a public digital archive of video recordings and motion captures of Cypriot folk dances. In 
addition, a 3D video game was created for children to be more aware of their dance heritage. The Bulgarian Folklore Digital Library (Pavlov, 2010) offers a web-based platform for the documentation and access to a range of Bulgarian folklore objects. Similarly, Artese built a web-based register for the intangible cultural legacy of the oral history of the Italian Lombardy territory (Artese and Gagliardi 2012).

3D modeling is usually used for virtual recreation of tangible cultural artifacts, but it can also be applied for intangible culture such as traditional festivals and ceremonies. For example, Choi work on the digital reproduction of the Yamahoko parade in the Kyoto Gion Festival through motion data of the oats and crowds (Choi et al., 2010), which allows people to have a realistic view of how the parade is like during the festival.

\subsubsection{Learning of intangible cultural content}

Hiyama explored new methods for archiving and transferring of craftwork skills. They built a wearable display system that can be used for the skill training on Kamisuki, Japanese traditional papermaking (Hiyama et al., 2011), replacing the traditional skill-transfer with word-of-mouth between a master and apprentices. It provided first-person visual and audio information and biological information (myoelectric signals, breathing and the eye-gaze) of a craftsman. Similarly, calligraphic skills can be trained through system that records an expert's movements and reproduces them through haptic devices (Saga et al., 2004).

Another work on calligraphy is by $\mathrm{Xu}$ (Xu et al., 2009), where an intelligent system was developed to learn the style of a particular calligraphist and automatically generate new calligraphy of the particular calligraphist.

\subsubsection{Techno-spiritual research}

Social values and beliefs are also an important component of the intangible culture. People from different cultural background inherently possess distinct way of thinking, feeling, and worldviews. However, the use of technology for them have been less explored, compared to other cultural contents described above. For example, despite the high-profile calls from Intel anthropologist Genevieve Bell to the HCI community for using technology in spirituality and religion (Bell, 2006; Bell 2007), research in this area is still rather sparse. In (Bluie and Blythe, 2013), they discussed the importance of supporting spirituality and religious practices in the $\mathrm{HCI}$ community, and proposed a few reasons for the lack of research in this area. Although in their paper the term "spiritual" is used in a loose sense, referring to a sense of deep connection to something larger than oneself, whatever that may be (a deity, nature, a cause, the Universe, 
an intimate group...), and covering all user experiences that can be described as spiritual, religious, transcendent, or numinous, thus it perhaps does not fully fit into the scope of intangible culture, we believe that the spirituality they talked about shares many common characteristics with intangible culture, and one of the important reasons for the lack of attention on them is probably the elusive nature that is hard to quantify, convey digitally and interactively.

Most techno-spiritual research mainly focuses on facilitating the spiritual practices using technology (e.g. using ICT for communicating religious messages (Bell, 2006), using tele-presence to help physically isolated people mediate together (Hlubinka, 2002), using sacred imagery in a mobile application to support Islamic prayer practices (Wyche, 2009), and a special display device to suggest topics for prayers (Gaver 2010), rather than embedding the cultural content in the interaction itself and creating new experience. The later approach requires analysis and understanding of the particular cultural contents to reproduce them in the interaction, and we can call them Cultural Computing research.

\subsubsection{Cultural computing research}

Cultural Computing not only concerns about integrating cultural aspects into interaction, but also allowing the user to experience the core elements of the culture through the interaction. The target of cultural computing is to extract a basic structure underlying a specific culture and to develop systems that would let people understand this basic structure through interactive experiences. Some work seeks to digitally model the intangible cultural contents, and allow people, especially novices to be able to participate in the creation process of the particular cultural content. For example, Yao et al. (Yao et al., 2010) digitized Shadow Play, a traditional art performance in China, using multi-point interactive control, which can be easily manipulated by a performer with no prior experience. Hitch Haiku (Tosa et al., 2008; Xu et al., 2009) is an interactive system that supports the composing of Haiku, a Japanese minimal poem form. Using this system, users can choose arbitrary phrases from a repository, and the system generates the Haiku based on the essence of words in the phrases. Similarly, Poetry mix up (Zhu et al., 2011) is a poetry creation system which models the words and structure of poetry. Users can get the system to generate their own poetry by simply sending an SMS to the system.

Another representative example is the project ALICE, which is an interactive installation that enables users to be immersed in a mixed reality environment featuring the story of the book Alice's Adventures in Wonderland by Lewis Carroll. Scenarios are selected and implemented as an interactive experience composing six stages, in each of which the user gets immersed in the installation, experiencing and rejecting on the western culture determinant (Hu et al, 2008; Rauterberg 2006). Another work is the 
Mysterious Machines, an art installation including three physical robots autonomously talking to each other as well as to the audience about religion issues (Schonenberg and Bartneck, 2010). It uses the New Testament, the Koran and Rigveda as the knowledge base.

For eastern culture, Tosa created the ZENetic Computer (Tosa et al., 2005; Tosa and Matsuoka, 2006), which projects the style of Zen communication into computing world, letting people experience Zen Buddhism through Sansui ink painting and construction of one's own virtual space. The system then generates a fragmented Zen story based on user's design of the virtual space, and poses Zen questions to the user. Through this interactive experience, users are led to confirm his or her self-awareness, consciousness and unconscious imagination.

Also about eastern culture, Uriu and his colleagues looked at how entertainment computing can be used to support Buddhism practices (Uriu, 2012). They use Augmented Reality technology to help users learn about Todaiji temple, one of the world heritages in Nara, Japan, and a special ritual ceremony held at the temple. Inspired by these work, we attempt to further cultural computing research by looking into Chinese philosophy and studying how to provide an interactive experience for the general public.

In the following chapters, three typical examples of Cultural Computing research will be described.

\section{ALICE}

\subsection{Cultural Computing: Western view}

The word culture (from the Latin 'colo, -ere', meaning 'to cultivate', 'to inhabit' or 'to honor') has been defined and used in many ways throughout different contexts. Kroeber and Kluckhohn (Kroeber and Kluckhohn, 1952) compiled a list of more than 156 different definitions for culture. One of the most popular definitions of culture in the field of anthropology is "a complex web of shifting patterns that link people in different locales and that link social formations of different scales." Culture is the integration of human behavior that includes attitudes, norms, values, beliefs, actions, communications and groups (ethnic, religious, social, etc.). Cultural computing is more than integrating cultural aspects into the interaction. It is about allowing the user to experience an interaction that is closely related to the core aspects of his/her culture. In a way that let him/her engage with an augmented reality using the values and attributes of his/her own culture. As such it is important to understand one's cultural determinants and how to render them during the interaction. In this paper we will focus on two cultural computing projects, one from the Eastern World (prevailing in Japan) and one from the Western world (prevailing in England). 
Over the last 3000 years the peoples of four distinct regions of the civilized world created the religious and philosophical traditions that have continued to nourish humanity into the present day: Confucianism and Daoism in China; Hinduism and Buddhism in India; monotheism in middle east; and philosophical rationalism in Greece. 'Monotheism' and 'philosophical rationalism' is the religious and cultural foundation of the occident. We have investigated illustrative stories that are well known, accessible, classical in their culture and relevant from the point of view of cultural computing. We primarily looked for narratives that would be helpful in the understanding of the essential aspects of both Japanese and English cultures. To this effect, we have selected the story of 'ZEN Buddhism' attributed to a Boddidharma (circa 500 AC), and 'Alice's Adventures in Wonderland' by Lewis Carroll (Carroll,1865). Both are detailed in the next sections, and both are examples either to help understand the underlying cultural value (i.e., Zen) or question it (i.e., Alice). For the Eastern and Western culture, the main value dealt with is enlightenment, but in different ways. Utilizing on modern technology Nakatsu (Nakatsu et al., 2006) try to give a new direction in form of 'Kansei Mediation' to enable societies transforming towards enlightenment (see also (Rauterberg, 2004)). Salem and Rauterberg (Salem and Rauterberg, 2005) discuss the relationship of cultural computing and entertainment, and $\mathrm{Hu}$ and Bartneck (Hu and Bartneck, 2005) could conclude that 'culture matters'.

\subsection{Western Culture: Alice in Wonderland}

In the West Kant (Kant, 1784) gave an answer to the question, "What is enlightenment?" He indicated that the 'way out' that characterizes enlightenment in the West is a process that releases us from the status of 'immaturity'; and by 'immaturity,' he meant a certain state of our will that makes us accept someone else's authority to lead us in areas where the use of reason is called for. In the Western world enlightenment is defined by a modification of the preexisting relation linking will, authority, and the use of reason6.

Nisbett (Nisbett et al., 2001) can confirm that Westerners are analytic, paying attention primarily to the object and the categories to which it belongs and using rules, including formal logic, to understand its behavior. In contrast East Asians are more holistic, attending to the entire field and assigning causality to it, making relatively little use of categories and formal logic, and relying on 'dialectical' reasoning. These Western and Eastern types of cognitive processes are embedded in different naive metaphysical systems and tacit epistemologies. Nisbett (Nisbett et al., 2001) speculate that the origin of these differences is traceable to markedly different social systems as part of the underlying cultural determinants.

To address logical reasoning in the western culture the most appealing narrative is 'Alice in Wonderland' of Lewis Carroll. Charles Lutwidge Dodgson (1832-1898), better known by the pen name Lewis Carroll, 
was a British author, mathematician, logician, Anglican clergyman and photographer. His most famous writings are 'Alice's Adventures in Wonderland' and its sequel 'Through the Looking-Glass'. His facility at word play, logic, and fantasy has delighted audiences ranging from the most naive to the most sophisticated. He was exceptionally gifted and achievement came easily to him. His works have remained popular since they were published and have influenced not only children's literature, but also a number of major 20th century writers such as James Joyce and Jorge Luis Borges. There are societies dedicated to the enjoyment and promotion of Lewis Carroll's works in many parts of the world including North America, the United Kingdom and New Zealand. In this perspective the book 'Alice's Adventures in Wonderland' can serve as input for a Cultural Computing project in the West.

The first interactive, but semi-immersive virtual reality system based on parts of 'Alice in Wonderland' was developed at the Entertainment Technology Center of Carnegie Mellon University. Pierce (Pierce et al., 1999) created a successful virtual experience based on a head-mounted display to overcome some or all of the following problems: entering a virtual world is a jarring experience, people do not naturally turn their heads or talk to each other while wearing a head-mounted display, putting on the equipment is hard, and people do not realize when the experience is over. In the Electric Garden at SIGGRAPH 97, they presented the Mad Hatter's Tea Party, a shared virtual environment experienced by more than 1,500 SIGGRAPH attendees. They addressed these head-mounted display related problems with a combination of back story, see-through head-mounted displays, virtual characters, continuity of real and virtual objects, and the layout and setting of the physical and virtual environment.

We started the cultural computing project ALICE as an interactive, entertaining experience (see Nakatsu et al., 2005) inspired from 'Alice in Wonderland'. In the scope of this project interactive adventures are experiences provided by an Augmented Reality (AR) environment based on selected parts from Lewis Carroll's book 'Alice's Adventures in Wonderland'. The user assumes the role of Alice and explores this interactive narrative.

ALICE is an exploration of interactive story-telling in AR. By exploiting the unique characteristics of AR compared to established media such as film and interactive media, the project uses AR as a new medium for edutainment and entertainment as a particular carrier for cultural transformations. Innovations include the refashioning of conventions used in film and interactive tools for the development of an AR narrative, and the use of simple artificial virtual and real characters (avatar and robot respectively) to create an immersive interactive experience.

ALICE is an augmented reality (AR) narrative with intelligent agents acting as characters who lead the user through virtual and real locations, moral choices and emotional states. The narrative is a surreal quest, sometimes funny, sometimes disturbing. The character White Rabbit (representing the concept of time) 
introduces him and joins with the user in a series of absurdist challenges. ALICE is an educational journey towards the user's heart's desire, designed to provoke self-reflection on a number of other issues: bullying and trusting others; selfish- and selfless-ness; enjoying the moment or sublimating pleasure. The user is given the opportunity to occupy and experience any of these mental and emotional positions. This will be achieved in line with the 'Alice in Wonderland' plot (albeit shortened).

Alice in Wonderland can be used to give interesting examples of many of the basic concepts of adolescent psychology. Alice's experiences can be seen as symbolic depictions of important aspects of adolescent development, such as initiation, identity formation, and physical, cognitive, moral, and social development (Lough, 1983). Alice's adventures are DE constructivist in nature and as such are directly challenging the strongly held belief of a linear, single track and sequential reality.

\subsection{ALICE: Implementing Cultural Computing in the West}

Our approach is to create an interactive experience based on the cultural values (e.g., highlighted in the story 'Alice in Wonderland'). A westerner would understand and appreciate the implementation of an interaction inspired from 'Alice in Wonderland8' adventures or 'Le Petit Prince', but will be puzzled if s/he was presented with an interaction inspired from the eastern 'Ox story' or 'The Journey to the West'. Similarly, an easterner would appreciate the second set and be confused by the first. Alice's adventures are illustrative of English culture. Indeed English and Western culture in general are based on Monotheist religions (Judaism, Christianity, and Islam) which are concerned with certainty and absolutism, in the sense of absolute truth and certainty. Western culture is also based on Cartesian logic and a linear and constant flow of time. To understand the culture shock that our proposed interactive experience could generate, it is interesting to look at the book 'Alice in Wonderland'. Alice, who is tired of the rational world she lives in and therefore follows the white rabbit into a hole, leading to a world without rational boundaries, experiences several culture shocks in this new world. Alice adventures happen in a world of paradox, the absurd and the improbable. The key aspects of Alice in Wonderland can be resumed in the following points: (1) a non linear non constant time flow; (2) a distortion of experience in space and with other characters; and (3) a counter-intuitive, common sense defying heuristics.

To be able to investigate the effects of cultural computing on the user's experience an interactive installation ALICE was build inside of the W-Hal building of the Eindhoven University of Technology. It takes a space of $12 \mathrm{~m}$ by $12 \mathrm{~m}$ spanning two floors over a total height of $7 \mathrm{~m}$.

The ALICE Installation consists of sixe consecutive stages. The visitor walks by him/herself through them, one after the other. Given the Western Culture's emphasis on individuality, the installation is designed for individual experiences. Figure 4.1 shows a schematic drawing of the installation. Notice the 
panoramic room on top, the spiral rail for the electric seat and the Cave in front. We will explain the function of each part in more detail within each of the corresponding stages. For each stage, the corresponding section of Carroll's original story is firstly summarized, followed by an impression of the design and the implementation.

\subsubsection{Stage 1: in the park}

In the first scene of Carroll's original book, Alice is bored and sleepy sitting on a bank with her sister. A white rabbit runs close by her and while looking at its pocket watch it cries out 'Oh dear! Oh Dear! I shall be late!'

Stage 1 symbolizes the concept of time. The visitor of the ALICE Installation enters this stage through two curtains. Inside, a 360 degree panorama picture of Cambridge surrounds the visitor, the place where Carroll lived and worked. The panorama depicts a location in nature at the river Cam (Figure 4.2).

The visitor is told to first fill in a questionnaire at a computer that is located on top of a tree trunk. Afterwards, the visitor is left to his/her own devices. The visitor has to wait until he/she is bored and thereby enters a similar state of mind as Alice in the original study. Then, a white rabbit appears from behind the curtain. It has a pocket watch and says through its internal speakers 'Oh dear! Oh Dear! I shall be late!' before disappearing into a rabbit hole at the far end of the room. On its way pass the visitor it tries to seduce the visitor to follow by starting a catch-me-if-you-can type of behavior. The rabbit enters a hidden section inside of the rabbit hole before the visitor enters the hole and hence disappears from sight. The visitor enters the rabbit hole after the rabbit and thereby enters stage 2 .

The panorama picture was printed on a large fabric. Several lights behind the fabric lighten the room and thereby giving the panorama the brightness of a summer day. The rabbit was build using a carbon fiber fabric. The model is mounted on top of a remote controlled car. A wide-angle video camera mounted in the ceiling allows the experimenter to see the whole room and thereby enable him to efficiently control the rabbit with the remote control.

\subsubsection{Stage 2: Down the rabbit hole}

Alice falls down the rabbit hole in an unusual fashion. The speed of her fall is very slow and she is able to interact with objects that are attached to the walls of the rabbit hole, such as cupboards and bookshelves. The fall takes such a long time that Alice engages in a conversation with herself before dozing off. At last, she lands on a heap of sticks and dry leaves. Stage 2 can be characterized by environmental space. Alice is discussing whether she can fall right through the earth and come out in New Zealand. She disputes the relationship of herself within the space of the earth. 
When entering the rabbit hole in the ALICE installation, the visitor finds an electric seat that is mounted on a rail. Once safely seated, the seat takes the visitor down a tunnel in spiral movement (Figure 4.3). Along the walls of the tunnel, cupboards, bookshelves and lamps are mounted. The speed of the electric seat is slow.

The seat was build using an electric stair lift, commonly used in the houses of elderly to enable them to move from one floor to another. A securely controlled gate prevents the visitor to pass by the seat and thereby endangering him/her to truly fall down the rabbit hole. The seat is only activated once the armrests are put down, which prevents the visitor from falling off while moving. Infrared cameras are placed inside the rabbit hole to allow the experimenter to monitor the visitor.

\subsubsection{Stage 3: Eat Me and Drink Me}

Alice enters a dark corridor with many doors, which are all locked. She approaches a glass table on which a small golden key lays. She uses the key to open a tiny door that leads to a garden, but Alice is too tall to enter. She approaches the table again, and this time she notices a bottle labeled 'Drink Me' and later a little cake labeled 'Eat Me'. By drinking from the bottle, she shrinks and by eating the cake, she grows. Eventually, she manages to have the appropriate size to enter through the tiny door.

Similar to stage 2, stage 3 is associated with the concept of space. Clearly, we could not grow or shrink the visitors directly, but we were able to manipulate their relative size in comparison to the environment by using a cubic CAVE. The walls and the ceiling were made of white semi-transparent material. We used the back-projection method to project a seamless virtual environment onto the walls of the CAVE. Figure 4.4 shows a scale model of the specially designed CAVE. A sliding side is connected to the entrance and the exit tunnels, enabling a 5-side full projection when the visitor is in the CAVE. Both the entrance and the exit tunnels are also build as a 3 -side projection CAVE, but for the time being only the exit tunnel is used for the stage 4 (the pool of tears).

The visitor entered the cave and had the impression to stand in a virtual room (Figure 5(d)). A cookies box labeled 'Eat Me' and a bottle labeled 'Drink Me' are placed on top of a small table (see Figure 6). When the visitor drinks from the bottle, the virtual room enlarges, giving the impression that the visitor is shrinking. When eating the cookie, the virtual room shrinks, giving the visitor the impression that he/she is growing.

On one side of the room, a door is shown. Once the visitor reaches the appropriate size, the wall on which the door is shown moves aside and thereby allows the visitor to enter stage 4 .

We used the Vizard VR Toolkit from Worldviz to synchronize the five projectors. The model of the virtual room was developed in 3D Studio Max. The floor of the cave is equipped with pressure sensors 
that allow us to determine the visitor's position in the Cave. Depending upon his/her location, the perspective of the projection is adjusted to give a true 3D impression of the virtual room. The bottle features touch and tilt sensors to detect drinking. The cookie box is equipped with a microphone that allows us to detect the visitor's chewing sounds when eating the cookie.

\subsubsection{Stage 4: The pool of tears}

During her growing and shrinking experience, Alice cries many tears. When she walks through the tiny door she enters a pool of tears. She talks to a mouse that swims along side her and together with some other animal they finally reach the shore. When the visitor enters stage 4 , the sea with a mouse in it is projected on one of the walls (see Figure 4.6). In addition, a smoke machine creates an impression of moisture and adds a mystical feeling to this stage. The visitor walks along the projection and thereby enters stage 5 .

At the beginning, we were discussing building a real pool, but it was not clear what the visitors would do with their clothes. Hence, we created a virtual pool of tears with the use of back-projection.

\subsubsection{Stage 5: Advice from a caterpillar}

The caterpillar engages Alice in discussion about herself. It asks Alice who she really is and how she wants to be. The complete episode is a dialogue and hence we created a robotic caterpillar to engage the visitor in a similar dialogue (Figure 4.7). Microphones recorded the utterances of the visitor and a simple dialogue system manages the conversation. Since most of the questions are metaphysical or mystical, a conclusive dialogue can be created without an extensive Artificial Intelligence (AI) for the caterpillar.

This stage can be associated with the concept of the self. Throughout history, there have been wide varieties of theories about the self, coming from the fields of philosophy, psychology, and religion. This includes assertions that there is no self; that the idea is a logical, psychological or grammatical fiction; that the sense of self is properly understood and defined in terms of brain processes; that it is merely a constructed sociological locus, or the center of personal and public narratives, or that it belongs in an ineffable category on its own (Gallagher and Shear, 2000). There is a significant difference in the construction of the self when comparing European/American culture and the Japanese culture (Kitayama et al., 1997; Nisbett and Masuda, 2003). By addressing the Western individual self-concept, Alice's self is challenged in 'Advice from a Caterpillar'. After she entered the rabbit hole to follow the White Rabbit, she experienced a lot of transformations both physically and mentally. This brought her in an initial state of confusion, which is emphasized in her conversation with the Caterpillar: 'Who are YOU?' This challenging attitude of the caterpillar makes Alice uncertain about herself, becoming vulnerable and open 
for persuasion (Fogg, 2003). Such a situation gives the possibility for a confrontation with and stimulates awareness of the self-concept. The character symbolized as a caterpillar is well chosen. One of the most important characteristics of caterpillars and butterflies is their unique life cycle. One of nature's most mysterious metamorphoses occurs when a caterpillar changes from a slow-moving, fat and ugly creature to a colorfully winged, beautiful butterfly. This metamorphosis happens to a lot of insects, but not as dramatically as it does to a butterfly (Heiligman, 1996). In this respect, the 'caterpillar' character can unconsciously pursue the message to a human user not to be afraid of a fundamental metamorphosis in his or her self-concept. This symbolic meaning can counterbalances the challenges intended by a conscious dialog next to it.

\subsubsection{Stage 6: The Cheshire cat}

The Cheshire cat involves Alice in a dialogue about logical reasoning and madness.

During the dialogue the cat disappears at times completely and sometimes only its grin remains visible. This episode of Carroll's book is predominantly a dialogue. In contrast to the previous stage, we did not use a robotic character, since the transformations of the cat are impossible in reality.

Therefore, we created a virtual Cheshire cat that is projected on a screen (Figure 4.8). When the visitor approaches the cat, it engages him/her in dialogue similar to the one in Carroll's book.

A Microphone was hidden next to the screen to record the visitor's responses. A simple 2D animation tool is used for the animation of the cat and the dialogue management. Similar to the Caterpillar, most of the questions are metaphysical or mystical, and hence a conclusive dialogue can be created without an extensive Artificial Intelligence (AI).

\subsection{Evaluation}

It is likely that the Alice installation will have an effect on its visitors, but it is unclear what effects and how strong they may be. The visitors' experience may range from being mildly entertained to a deeper psychological disturbance. Currently, we are planning a first experiment and in the following paragraphs we describe the approach we intend to take. The experiment will be setup as a repeated measure study. Each participant will be measured before and after visiting the Alice Installation. The within-subject setup will decrease the effect of individual differences.

Since the effect of the Alice installation is unknown, we intend to use several measurement instruments that cover a wide range of concepts. This wide spread of measurements will reduce the risk that we may miss an important effect. In a second experiment, we will then be able to focus on those measurement instruments that proofed to be sufficiently reliable and sensitive. We will discuss our choices for 
measurement instruments in order of the six stages in the Alice installation and their corresponding theme.

After two preliminary studies of single stages (Kooijmans and Rauterberg, 2006), we are currently planning a first experiment for the complete installation. The experiment will be setup as a repeated measure study. Each participant will be measured before and after visiting the Alice Installation. The within-subject setup will decrease the effect of individual differences.

The first stage is associated with the concept of time. Fraisse (Fraisse1984), Nakatsu,

Rauterberg and Salem (Nakatsu et al., 2006) argued that "the more one pays attention to time, the longer it seems, with the extreme being expectancy which is nothing but expectancy of a desired or feared event. Reciprocally, duration seems short when the task is difficult and/or interesting."

Since, we are not primarily interested in the influence of expectation on the perception of time (e.g. 'A watched kettle never boils' (Flaherty, 1999)) we will focus on retrospective duration similar to Glicksohn's (Glicksohn, 1992) study. His study showed that retrospective estimation of the duration to an altered sensory environment was not affected by the environment, but the method of production registered an influence on the participants' cognitive timer.

Stages 2 and 3 deal with space. Stage 2 can be characterized by environmental space, while stage 3 is associated with personal space. In both stages, the relationship between the visitors' and the installation's space is of essence. This relationship can be described within the well-established framework of Presence. The Independent Television Commission - Sense of Presence Inventory (ITC-SOPI) questionnaire (Lessiter et al., 2001) is the de facto standard tool to measure presence and has previously demonstrated its usefulness (Hu and Bartneck, 2005). We therefore included it in our study.

The symbolic interpretation of the stage 4 remains difficult. A possible symbolism could be the Christian ritual of baptizing. We were not yet able to identify an operationalization of the genesis concept for this stage. This stage is also very short transitional phase in the installation and hence we may neglect. We will continue our effort and would be grateful for suggested from the reader.

Stage 5 is associated with the concept of the self. The Alice installation is expected to not only influence the consciousness, but also the unconsciousness of its visitors. We intend to measure the visitors' conscious perception of the self through a personality test based on the NEO Five-Factor Inventory (NEO-FFI) with 60 items, which is designed to take only $15 \mathrm{~min}$ to fill in. For the unconscious self-concept Greenwald, McGhee and Schwartz (Greenwald et al., 1998) developed the Implicit Association Test to overcome this limitation and demonstrate its effectiveness to measure the self-esteem and -concept (Greenwald and Farnham, 2000). 
The necessity of logical reasoning is the topic of the last stage. Generating alternatives is a key component in human reasoning (Newstead et al., 2002) and hence we use the Alternative Generation Task originally proposed by Torrens, Thompson and Cramer (Torrens et al., 1999). Participants are being asked to create as many diagrams as they could think of to visualize a multiple model syllogism. Their responses were scored in terms of the number of different but correct diagrams produced.

\section{ZENetic Computer}

\subsection{Cultural Computing: Eastern (Japanese) view}

Since involving various kinds of media technology in our everyday lives, we have built a sphere of communication that reaches to all parts of the globe. However, on the other hand, we are starting to feel the danger that, as the communication network expands, the level of personal communication has become shallow.

In this situation, a new communication medium that will convey personal depth of feeling across long distances has become urgently necessary. Within this context, we decided with this project to pursue the possibility of a communication medium that incorporates a new kind of interactivity, with editorial engineering (Matsuoka, 2001) and art and technology (Tosa, 2000) as a foundation, and including research on the operation in which interactions of multiple cultures come to fruition, and research on the "intelligence" that appears in between the user and the system.

Human communication is originally something cultivated in an environment comprising localities, national customs and language. Therefore, the fruits of these cultures have strong roots in their unique histories.

However, the media that developed in order to convey these peculiarities across cultures were communication media such as writing, music and film. Now, as the computer society covers the earth, the task that computers must take on is the clear and accurate intercommunication between local and global cultures. Toward that end, it is first necessary for those involved with computer technology to bring to life local characteristics.

Thus, the authors focused on the cultural roots of their native country, Japan. This includes Buddhist culture, the kanji culture, haiku and other Japanese poetry and song, and traditional Japanese dress (kimono). They decided especially to dig into the unique communication space and imagery methods developed in Zen Buddhism and landscape ink painting (sansui painting).

Within the traditional relationship between culture and computers, emphasis has been placed on the 
preservation of decaying traditional cultures for the sake of future generations, restoration of artifacts, and computer graphics simulations recreating lost relics. However, the authors struck on the possibility of computing the previously unquantifiable essence of culture inherent within people, such as personal subjectivity, feeling, emotion and cultural personality (Murray 1998).

With this research project, the authors offer the concept and direction of "cultural computing" as above, and describe, in simple terms and through the realization of an actual interactive system, a computing method reflecting the differences of emotion, consciousness and memory that will be indispensable for the future communication abilities of computers.

As Cultural Computing is a very broad field, in order to produce a specific example, one must pick out a single local culture and use that as a base for building a real system. In this case, we chose Zen, a special area of Buddhism, and developed and evaluated ZENetic Computer as a system in which people can experience Zen culture firsthand.

\subsection{ZENetic Computer: Concept}

We developed ZENetic Computer as a specific example of Cultural Computing. We focused on the roots of Japanese culture, including Buddhist culture, kanji culture, waka and haiku poetry (Matsuoka, 2004). We decided to especially focus on the unique communication space Zen and sansui ink painting create.

Below is explained the scenario a user experiences within ZENetic Computer. First, the user builds a three-dimensional sansui ink painting on the display using an intuitive and user-friendly interface, constructing her own virtual space.

These images express the natural world that characterizes the East and Japan and their philosophical concepts, providing the user with a dramatic experience very different from the images seen in modern-day life (Matsuoka 2003). In this way, in the introduction, the system brings about a kind of awakening within the user, and encourages their unconscious imagination.

Next, as the system classifies the user's state of consciousness based on the composition of their sansui landscape design, it generates a story appropriate for the user, drawing her through the display into this alternate world.

Within the story are included mechanisms to shake the user's consciousness developed from haiku poetry and Zen riddles (koan). The story built from these elements is not a complete linear story like those found in movies or novels, but rather a nonlinear collection of short story fragments. A user who experiences these inconclusive story fragments feels a kind of uncertainty, and holds an expectation and desire to build a complete story by connecting these fragments. Because of this desire, the user, in being asked questions without a "correct" answer, may hesitate somewhat but cannot help but try to answer these 
questions.

Through several such triggers lurking within the center of culture, the user connects these stories and builds her own unique narrative. Next, as the user uses a virtual brush, a rake for the rock garden, and images within the screen in response to questions posed by the system via images and voice, she begins to realize that the system is demanding that she meet it face-to-face. This means the door to her "unified consciousness" has begun to open further. As our desire to connect the story fragments mixes with the system's user interface, the distance between our every-day self and our true hidden self begins to shrink. $M a$ interaction plays an important role in the process of fusing together these two selves. $M a$ is a very Japanese concept; it is one that places a high value on ephemeral events - the here-and-now - within every experience.

The user, having thus traveled through several stages and several scenes, now coming to the end of the trip, interacts with a bull, which is used in Zen as a metaphor for expressing one's true self. Through this dialogue, the user can experience the process in which the everyday self and the subconscious self fuse together bring about a unified self-consciousness.

As the surrounding environment plays a very important role in this experience, we have made an effort to conjure an Eastern atmosphere for the ZENetic Computer installation. (Figure 5.1)

\subsection{Story Generated from Symbols}

\subsubsection{Creation of a typical Sansui painting}

We divided sansui painting into twelve hieroglyphic characters (rock, mountain, moon, traveler, bridge, bird, tree, flower, wise man, cloud and water) and made them into icons. The user drags any 2D icon and constructs his or her own 3D sansui painting. Figure 5.2 is an example user-constructed sansui painting.

\subsubsection{SaNen design}

As one can see in the Sesshu painting in Figure 5.3, there is a unique method of perspective for sansui paintings called sanen. Within the painting are three perspectives: koen, lying far away with a view from below; heien, with a straight-on view; and shinen, close-up and viewed from above. Depending on the position of the user's icons, graphics corresponding to the sanen area are displayed, increasing the realism of the user-created sansui painting.

\subsubsection{Interactive story generation}


When the user finishes creating the sansui painting, she can walk through the three-dimensional sansui space she created by operating the "rock garden interface" containing a touch panel (Figure 5.4). By the user's approaching any sansui painting icon within the space, a haiku poem or Zen dialogue is output based on the combination of sansui painting icons contained in the framed display.

\subsection{Interaction Model Using a Buddhist Human Recognition Model}

We include the Buddhist communication method between Zen master and pupil, a fashion for the purpose of understanding people, which has been followed for over 2,000 years. This kind of interaction based on the deep understanding of people is a field not yet researched within Western science.

\subsubsection{Sansui world expression based on world model "Godai" (sky, water, fire, wind, earth)}

In Buddhism, the directions and the five elements (godai) constructing the world are closely related. Upon walking through the sansui painting world, changes in weather based on godai appear depending on the direction of movement. For example, weather changes such that if one goes north, it snows; south, a thunderstorm appears; east, it gets foggy; and west, it rains.

\subsubsection{Classification of user personality based on personality recognition model}

Goun are the elements that make up the core of the Buddist thought in which five basic physical and mental elements make up the world; in this interactive system, we apply these elements in the classification of personality. The five personality categories are as follows:

色 (Shiki) How nature and materials actually exist

受 (Jyu) Intuitive impression

想 (Sou) Perceived image

行 (Gyou) Process of mind that activates behavior

識 (Shiki) Deep mental process reaching beyond the above processes

We prepare a two-dimensional goun space made up of 10 areas with these values along the vertical axis and their strength (positive or negative) along the horizontal axis. When the user generates a sansui landscape according to her preferences, the system classifies the user's individuality through the combination of goun categories assigned to the icons that make up the landscape. Through this process, the user's individuality is expressed as a goun value, and the initial value is determined as described above. 


\subsubsection{Zen dialogue interaction}

When the user approaches a certain object within the sansui painting, a Zen event occurs. Every event is constructed such that one can have an interactive pseudo-real experience with a Zen koan. The User, Target and Zen Master agents exist within each interaction, and the content of the interaction changes based on their interrelationships.

For example, the koan "Dharma Anjin" (Figure 5.6) is a dialogue where once, in response to a pupil's complaint that his inner spirit is in turmoil even after training, Dharma replied "Alright, then show me your troubled spirit." We have translated this into an interaction in which one draws one's inner spirit. The koan "The Lotus Smiles" (nengemisho), shown in Fig. 7, holds the meaning of telepathy. In order to express this, we made an interaction like a matching game, hiding Noh Theater masks beneath lotus leaves, such that the leaves change to flower petals when the user finds matching masks. Fig. 8 is the koan "the Sound of One Hand Clapping," wherein the system judges the calmness of the user's spirit by measuring the regularity of the user's hand-clapping.

\subsection{Interaction Control via Chaos}

One can think of the interaction for the Zen dialogues as being controlled by a combination of both cooperative and oppositional interactions between three different states: (1) the current state of the user (User), (2) the goal the user should reach (Target), and (3) the Zen master that guides the user (Zen Master). To simulate this process, a model is used such that the reaction of the system during user interactions depending on the interaction of the three elements of User, Target and Zen Master, which are all expressed as points with Goun space. As a method to implement this model, one can think of a way to show the positional relationships between the three elements and the system's reactions as a table. However, because with this method the system's reactions become fixed, one cannot realize a framework allowing the enjoyment of various kinds of interactions spanning several uses. In order to allow many users to experience various interactions each time they interact with the system, it is helpful to introduce an appropriate element of "fluctuation."

The system uses a method for the dual synchronization of chaos to realize this fluctuation (Liu and Davis, 2000). The method for dual synchronization of chaos is a model handling the synchronization of three or more chaos states. In this case, the system adopts a model containing three chaos states, corresponding respectively to the User, Target and Zen Master. Each chaos state corresponds to a point in goun space. Under the method for dual synchronization of chaos, if one applies an initial value and an appropriate input value, the three chaos states relate to one another, moving through goun space, and generate an output corresponding to their interactions. For the chaos input, the system uses data from the user's 
interactions. With the basis of Zen, activity, as the axis, the goun value rises (in the plus direction) the more active a user's interaction, and falls (in the minus direction) the less active he is. The data output from the chaos model is used after transformation into the system's reaction data for the user. For example, in the koan "Dharma Anjin," the position of the Target chaos changes depending on the curvature and density of the drawing the user sketches. The higher the density and curvature are, the better goun state achieved. In order words, the Zen "enso" (circle) is the best. Also, in "the Lotus Smiles," the goun state rises with a higher accuracy in matching images of Noh theater masks.

\subsection{The Flow of the Story Experience within Sansui Space}

The story process a user walks through is as follows

1. Generate a sansui painting

2. Haiku are generated related to the icons on the sansui painting

3. When the user approaches objects in the sansui painting, associated Zen dialogues appear

4. Depending on the interaction results from the four Zen dialogues, a form matching the user's personality is determined from the following four forms of Japanese culture:

5. In conclusion, the "Ten Ox Story" corresponding to the user's interactions is displayed.

\subsection{Evaluation and Future Outlook}

At the $32^{\text {nd }}$ UNESCO General Conference, the meaning of culture was defined once again. Culture encompasses all of customs, images, expressions, knowledge, skills, as well as related tools, goods, artificial objects and cultural spaces. Not only physical cultural relics, but also information exchange systems, communal, spiritual, and philosophical systems are included in the definition of culture.

In 2004, ZENetic Computer received second place in the UNESCO-sponsored Digital Storytelling Competition of Intangible Heritage. In the future, as the processing power of computers, high quality displays and input devices approach the limits of human perception, it is expected that high technology will enter the spiritual domain. In the West, Japanese Zen is an old and mysterious philosophy. Indeed, although books try their hand at explanation, it is difficult to truly understand Zen by reading alone. ZENetic Computer tries to convey the spirit of a culture through experiences such as participating in Zen dialogues, listening to haiku and exploring kimono patterns.

In the future, there will likely be a strong desire for the thought and design of cultural computing for universal communication, boldly making this kind of cross-cultural connection. This project was planned with this intent in mind, and for its realization the authors made use of advanced game design, graphics, and interactive displays. We are certain that the methods used in ZENetic Computer will flourish in the 
broad field of education and will make possible experience-based cross-cultural understanding.

\section{Confucius Chat}

\subsection{Cultural Chat: Eastern (Chinese) View}

Confucian cultural values and teachings are traditionally preserved in printed media, for example books. They are often written in an esoteric way which has not only limited appeal to young users, but their sheer volume simply intimidates many. Existing endeavors in making traditional texts friendlier to young readers have rarely gone beyond the hard-core medium of books - the methods they employ include adding modern language interpretations, or inserting caricatures to assist understanding. The phenomenal sales for such products indicate a high demand for Confucian knowledge in modern Chinese societies. Others have ventured into the television media by producing cartoon series featuring Confucian figures and their stories. However, this method transforms young people from active readers to passive receivers. Current projects utilizing the Internet as medium are limited at digitizing ancient texts and creating electronic databases, whose primary purpose is to facilitate academic research. Example of such electronic databases includes the electronic version of Siku quanshu (the Imperial Collection of the Four Treasuries ). However, since such databases are created and managed by academic institutions, which often impose restricted access, people outside the academia are excluded from its usage. Moreover, for users to make meaningful use of such electronic resources, certain knowledge of the entire corpus is necessary before they can make sense of it.

Young people of today possess high level of digital literacy. Through modern networked and social media such as Facebook, Twitter, etc., they make friends, explore new forms of entertainment, seek advices and expand their knowledge (A Common Sense Media Study, 2012; Nielsen Study, 2009. It is evident that new media is an appealing and natural information seeking channel for today's young generation. We see cultural computing (Tosa, 2010; Rauterberg 2006) as a promising approach to promote traditional culture to the young people today. By embedding the cultural values in the interactive experience, it naturally conveys the information and nurtures cultural understanding. Inspired by the cultural computing project ZENetic Computer (Tosa 2006), we designed Confucius Chat, a system that presents the age-old Confucian philosophy in the new context of interactive media. Here, users are no longer passive receivers listening to lectures of Confucius; instead he/she will be active enquirers engaging in stimulating dialogues with him. By bringing users 'face to face' with the historical giant who share with them his life experiences and the joys he derived from pursuing the Dao (the Confucian Way of moral ethical being), 
we hope to dispel the misconception that the Confucian way of ethical being is no more than an ascetic life of self-restrain. By using interactive media - one of the best parts modernity provides us - we attempt to revive the appeal of these ancient philosophies and teachings to our young generation, and thereby, do our part in promoting traditional Chinese culture and closing the gap with the older generations.

\subsection{Methodology}

The Confucius Chat project has been a joint effort of an interdisciplinary team consisting of both Confucian scholars and computer scientists. The Confucian scholars collect relevant text materials needed for creating the virtual Confucius, whereas the computer scientists are responsible for designing the algorithms dealing with the materials collected. Both parties work together to discuss how to model Confucian knowledge and present it to users.

We create a knowledge base of Confucian statements from four classical texts: the Analects, Confucius sayings in the Mencius, passages directly related to Confucius in the Book of Rites and the entire Classic on Filial Piety . These four texts constituted a major part of the educational curriculum for children in imperial China (De Bary, 1996). They are the classics par excellence in the vast sea of Confucian corpus, and textual basis of the culture in which the older generation of Chinese immersed. We chose to use James Legge's (1815-1897) translation for all four texts. Since his translation is one of the earliest English translations, and is less literal, we hope it can produce a more archaic tone in virtual Confucius's replies, thereby inducing a more historic experience within users - the feeling that he is actually talking to someone walking out of history. On encountering disputable interpretations, we will consult two other commonly used translations in the field by D.C. Lau and Simon Leys to derive at what we think is an appropriate, and more pertinent translation to our modern day user.

We eliminate passages that are too historically specific in nature, out of which no real meaning can be extracted. Also, since many of the passages are lengthy (especially those in the Book of Rites and the Classic on Filial Piety ), and are comprised of several parts each with a distinct meaning, instead of transporting the whole paragraph of text into our knowledge base as one entry (i.e. one sentence that can be used as the reply from the virtual Confucius), we separate them into short but self-sustained statements. For instance, the opening passage of the Analects becomes three entries in our knowledge base: 1 . Is it not pleasant to learn with a constant perseverance and application? 2. Is it not delightful to have friends coming from distant quarters? 3. Is he not a man of complete virtue, who feels no discomposure though men may take no note of him? In this way, we gathered 2069 entries in total. 
A topic table is created to describe the contents of the collection through card sorting technique. Topics are classified into eight headings: Action/conduct, virtue/morality, social relations, emotions/feelings, governance, metaphysical concepts, life circumstances and places/areas. Under these headings there are a total of 269 topics. We include in our topic table the corresponding meaning of the words as they are used in the classical texts. Word meanings are based on the WordNet (Fellbaum 1998) lexical database. This is necessary, because many of the topics in this domain have special meanings, which makes literal word-level tagging insufficient. For each entry in the knowledge base, 1-3 topics are identified. For sentences containing domain-specific terms (e.g. special concepts, name of historical persons and texts, etc) that do not have a semantic meaning in the WordNet, a separate database tagged with these terms is created.

In addition to the philosophy knowledge base, we also create a knowledge base of answers to questions about Confucius as an individual, for example, his age, date of birth, hometown, etc., as well as information about his disciples, gathered from the earliest reliable historical text of Shiji (Records of the Grand Historian), by Sima Qian (ca. 110B.C.). These question and answer pairs are stored as patterns and templates in the Artificial Intelligence Markup Language (AIML) (Wallace, 2003). AIML is a commonly used language for building natural language chatterbots. Though it simply relies on pattern matching, it is extremely effective in making the agent seemingly intelligent and human-like.

Furthermore, we also prepared a few series of dialog sequences, which would be initiated by the virtual Confucius asking the user a question. This would make the conversation between the user and virtual Confucius more interactive.

\subsection{System Description}

Building upon our previous web-based proof-of-concept (Khoo, 2009), we have designed a system where users can directly have a conversation with a virtual Confucius through a mobile device. Users can think of it as a virtual sage living inside their mobile phones. It allows people to interact with the virtual Confucius anywhere and at any time, thus providing a more convenient way to get exposed to traditional cultural values. In this second iteration of our development, we greatly expanded the knowledge base of the system by working with Confucian scholars who gathered a comprehensive collection of Confucius's sayings, and redesigned the algorithm accordingly. This process will be described in this section.

To create the virtual Confucius, we first worked with a few Confucian scholars who have the domain knowledge to build a knowledge base containing sayings from Confucius. The sayings were collected from four classical Confucian texts - the Analects, the Mencius, the Book of Rites and the Classic on Filial Piety. The Confucius scholars were asked to manually annotate the knowledge base by labeling 
each entry with their corresponding topics. We then built a Confucius thinking engine utilizing various Natural Language Processing (NLP) techniques to analyze user inputs and extract answers from the knowledge base.

We employ a layered approach for the input analysis and answer generation. Depending on the nature of input questions, three methods are designed to retrieve suitable answers from the knowledge base. Input sentences from users are processed by these methods sequentially, and the system decides if the answer is suitable for output based on certain quality measure. A flow diagram of this process is shown in Figure 6.1 .

Firstly, an adapted A.L.I.C.E (Artificial Linguistic Internet Computer Entity) program (Tsai 1996) is used to search for an answer. This method relies on pattern matching to find a suitable reply in pre-scripted question and answer pairs. The original scripts were modified by the Confucius scholars, tailored to Confucius's personal information and personality. This method works well for handling small talks, such as saying hello or introducing himself. If the question is out of scope of the adapted A.L.I.C.E knowledge base, a series of NLP techniques are used to analyze the input sentence and relate it to the sentences in the knowledge base of Confucius's sayings. We applied a grammatical parser (Klein,) 2003 to understand the structure of the sentence, extract the keywords in the sentence (Huang 2008), and match their semantic closeness (Pedersen, 2004; Pedersen, 2009 with the topics in our knowledge base, with the help of a lexical database called WordNet (Fellbaum, 1998). The sentence in the knowledge base with the highest similarity score is selected as the output. This added layer of semantic comparison gives the system the ability to dynamically calculate and respond to unseen inputs, in contrast to other commonly available conversational agents that mostly rely on pre-scripted answers. In addition, a simple word-matching module was also implemented, in case the previous two methods failed to find an answer. It also has one important function that is necessary in the system - to handle domain specific terminologies that do not have semantic meanings. Finally, if no suitable output can be found using the above-mentioned methods, a default output will be presented, asking the user to rephrase the question.

The iSage thinking engine requires a large comprehensive lexical database and is computationally intensive. Considering the computational power of mobile phones and the wide availability of $3 \mathrm{G}$ and Wi-Fi networks today, we decided to put the core data processing modules in our server rather than on the mobile phone itself. The mobile application simply accepts the user query and sends it as an HTTP request to the server. The server receives the request, processes it, and sends back the answer retrieved using the iSage thinking engine. The answer is then displayed on the mobile phone as virtual Confucius's reply. Figure 6.2 shows the architecture of the system. Currently, user's chat history with the virtual Confucius is logged anonymously for data collection and analysis in the future. 


\subsection{Usage}

Figure 6.3 (a) shows a screenshot of the iSage application when it is opened for the first time. Users are informed that this application is part of a research project and the data will be logged anonymously for research purpose. After they acknowledge it, the main page is shown as in Figure 6.3 (b). To chat with the virtual Confucius, users can type in the question in the text box, and press the green "Ask" button next to it (Figure 6.3 (c)). The question is then sent to the server, which replies with virtual Confucius's answer after processing. The answer is displayed in the area above the text input, as shown in Figure 6.3 (d). Users can share the answer to their friends to their social networks, such as Facebook, Twitter (Figure 6.4 (e)). We hope to leverage the power of social networks to spread information about the application and the words from the virtual Confucius, so as to get more people to know about it and thus further promote interaction with traditional Chinese culture.

Users can also rate the given answer if they think the answer is funny, profound or bad, by pressing the corresponding icons at the bottom of the screen. The "Bad" rating works as a feedback for us to find out the problem of the algorithm, so that we can improve it further in the future. By tapping the "Top" icon, users will be led to another page where they can see the top 10 most funny and most profound question and answer pairs from all users (e.g. Figure 6.3. (f)). The latest 10 question and answer pairs can also be viewed (Figure 6.3. (g)). This allows users to see what other people are asking the virtual Confucius, so they can get more inspirations or just to have a laugh. Users can also vote for the question and answer pairs here, simply by tapping the particular question and answer (Figure 6.3 (h)).

\subsection{Evaluation}

To see people's reactions to this system as a new way to interact with culture, and to gather feedbacks to further improve the system, a preliminary user evaluation was conducted with 20 participants. All of the participants are university students and researchers under the age of 35, representing the relatively younger generation who are not so familiar with traditional culture, but are frequent users of the Internet and multimedia. All of the participants are Asian except one, but most of them indicated that they are not very familiar with Confucianism.

The participants were first informed that he/she was going to interact with a virtual Confucius, which is a computer program that tries to mimic the real Confucius. They could use this mobile application to converse with Confucius, and they could ask any questions they like. The participants were asked to interact with the system for about 10 minutes and fill in a questionnaire afterwards to report their experience with the application. 
Almost all participants indicated that they enjoyed interacting with the application. A majority of them said they became more interested in Confucian culture and would like to know more. It was agreed by most of the participants that it is a good idea to promote ancient culture through this system, and it was more fun to interact with the system than reading a book about Confucian philosophy. However, when asked about the actual effects as compared to book reading, many of them hold a conservative view. Some reported that sometimes it was difficult to understand the answer from the virtual Confucius, and suggested to phrase the answer in simpler language and further improve the algorithm to produce more relevant and meaningful answers.

\subsection{Conclusion}

We see great potential in combining culture with new media technology. As our first attempt, we have created and published a virtual Confucius that can talk to people. We hope that real users can use our system, and enjoy this new experience interacting with ancient philosophy. It is not meant to replace book reading or classroom learning. Instead, by making the classics more approachable, we hope to help dispel the common stereotype of a pedantry Confucius who only lectures and preaches [1], and arouse the young generation's interests in Confucian philosophy.

Though our preliminary evaluation showed that the application was successful in capturing user's attention and interests, as users only interacted with the system for a very short period of time, the real benefits of using this system, especially how much users can actually learn by interacting with the application, are still unknown. It also presents great challenges for evaluation in this respect - unlike science or history learning where there can be standard tests, culture is much more abstract and difficult to measure. One possible method is to conduct semi-structured interview with the participants before and after longitudinal use of the application. Scenario-based questions can be designed by domain experts and used to assess user's knowledge and understanding of the Confucian culture. We will explore this in our future work.

\section{Media Art}

\subsection{Definition}

Media art is a new genre of art that started in 1960 and is becoming more and more popular in recent years (Tribe et al., 1995; Shannen, 2014). Media art covers very wide area ranging from film art, photo art, 
video art, interactive art, virtual reality art, network art, and even game art.

The reason why this new art area is called media art is that, different from conventional media such as papers, marbles, rocks, etc., it's exhibition in its deliberation process and exhibition process, new media have been mainly used such as film, video, photo, installation, network, projection, and communication media such as e-mail, SMS, ad even online games.

The most distinctive feature that differentiates media art from conventional form of art, usually called 'fine art', is that various types of technologies are tightly connected with artistic methodology and plays a substantial role to create new type of art (Candy and Edmonds, 2002: Jones et al., 2006). These technologies film technologies, video technologies, human-computer interaction technologies, communication technologies, virtual reality technologies, projection technologies, network technologies, communication technologies, game technologies, and so on.

These technology help artist to consider artistic concept, express artistic concept, create new art form, and create new ways of delivering and exhibiting artworks. One distinguished example is an emergence of 'interactive art.' Although there has been no direct interaction between viewers of artwork and artwork, by introducing human-computer interaction technologies, it became possible that artworks can change their forms based on the interaction between the viewers and the artworks (Sommerer and Mignonneau, 1999). This can open up a totally new type of art creation/anticipation process, although its full realization would take a long time.

Although there have been a lot of art exhibitions treating media art at museums, galleries all over the world, from business point of view this new art genre has not yet been fully recognized by people. There are only a few museums and a few art collectors that have collected media art as one of their collections. However in this area also the situation is changing. Some of video artworks created by well known vide artist are sold and/or bought by many museums and art collectors.

\subsection{History}

The history of media art traces back its origin to 19th century when several types of pre-cinema invention such as Zoetrope, Praxinoscope, Zoopraxiscope appeared (Leeman, 1976). Then the era of cinema came when Auguste Lumiere and Louis Lumiere invented cinematographe (Whiting, 2005). Although most of the previous art forms, except performances, were static, cinema introduced moving images as a new expression form of art.

In mid 20th century various types of kinetic art and light art. Thomas Wilfred's light artworks (Betancourt, 2006) and Jean Tinguely's kinetic artworks (Tunguely, 1988) should be noted as representative pre-media artworks. 
Then the era of video artwork came in 1960. In this genre representative video artists are Nam June Park and Wolf Vostell (Higgins et al., 1971). Nam June Park' solo exhibition in 1963 is recognized as a first video art exhibition in the world. As video artwork is becoming a target of art collectors interest recently, the contribution of Nam June Park and Wolf Vostell should be memorized as a significant mile stone in the history of media art.

Along with the advancement of computer technologies and computer graphics technologies in 1970s and 1980s, various new types of media art appeared. For example Ivan Sutherland invented HMD (head-mounted display) and also various kind of computer graphics algorithms which makes it possible to create various new at experiences in computer graphics based virtual environment. Also new exhibition opportunities for media art were generated during this era. One is Ars Electronica (Stocker and Leopoldseder, 2014)) Center in Australia, a center focusing exhibition of media and, and another is SIGGRAPH, a conference and exhibition focusing computer graphics technologies and their applications. 1990s is another memorable are for media art. With the advancement of human-computer interactions and real time technologies, it became possible for computers to react humans action in real-time which make it possible for a new media art called interactive art to emerge. Various types of interactive artworks were created and exhibited as installations. Several representative artists in this area is Roy Ascott (Ascott, 2003), Chirista Sommere \& Laurent Mignonneau (Sommerer and Mignonneau, 1999), Naoko Tosa (Tosa N, 2015), etc. Ars Electronica and SIGGRAPH (for example see ACM, 2000) offered good opportunities for these artists and their artworks.

Also new museums, centers dedicated to media art, especially focusing this new media art of interactive art were built and started their activities. Some of the representative museums and centers are ZKM (Center for Art and Media) in Karlsruhe, Germany (Schwarz HP, 1997), ICC (Inter Communication Center) in Tokyo, Japan (see http://www.ntticc.or.jp/index_e.html).

Although the basic concept of interactive art which makes possible for interaction between viewers and artworks and through it even interaction between viewers and artists is totally new and is innovative even now (Nakatsu, 1998), unfortunately there have been only a few interactive artworks that fully incorporate this concept. Therefore in 2000s people's interest in interactive artworks has decreased a bit, although still at interactive art exhibition at SIGGRAPH and Ars Eletrnica are the centers of researchers and artists attractions who are working in this area.

However in fine art area the recognition toward media art as a new genre of fine art has been shared among museum curators and art collectors. Therefore in world famous art shows such as Art Basel, Hong Kong Art Show, many new media artworks are exhibited along with traditional fine artworks and such new media artworks became as a target of art collectors' target. 


\subsection{Art and Culture}

From its origin, art has had a close relationship with culture. There are many artworks that record and/or illustrate various kinds of cultural issues such as cultural events, cultural customs, cultural heritages, etc (Benton and DiYanni, 2011; Greenberg, 1971). Also there are lots of artworks that illustrate religious issues all over the world, such as various religious events, pictures of famous religious saints, etc. As religion is a key part of culture, this means that art has been closely involved in culture (Plate, 2002). Even now especially in under-developing countries and in rural areas in developed countries, there are many artist who are trying to draw cultural life of people who live there.

In the case of media art, however, the situation is somewhat different. As was described before, one of the distinguished features of media art is that technologies are tightly connected to various aspect of artworks such as conceptualization, creation, exhibition, deliberation, etc. This means that technologies play an essential role in media art. Technologies have been usually indifferent to cultural issues and in some sense, based on their futuristic concept, technologies have been trying to change people's everyday customs/habits which means that technologies have been even destroyers of cultures.

Therefore unfortunately until recently the relationship between media art and cultures have been week. The emergence of the concept of Cultural Computing has been changing this situation. As technologies would make it possible for computers to treat cultural issues, also in the area of media art it is expected that gradually media artworks would emerge that treat cultural issues.

Here treating cultural issues should be more than simple recording/preserving cultural events, heritages, etc. Three good system examples of Cultural Computing, ALICE (Hu, 2008), ZENetic Computer (Tosa, 2005), and Confucius Chat (Wang, 2013), were described and discussed previously in this chapter. It should be emphasized that what the researchers of these systems tried to do is, based on the deep understanding of their own cultures, to try to develop systems that make it possible for young generation and people in different cultures to be able to understand long-time existing rich cultures or their own.

Therefore the relationship between media art and culture should also target the same direction. The role of media art when treating cultural issues should not be the simple recording/expressing of cultural issues but should be something deeper. As an good example of such integration between media art and cultural issues will be described in next section.

\section{Media Art Treating Cultural Issues}




\subsection{Background}

Big events such as art exhibitions, technical exhibitions, etc. is a good chance to demonstrate the achievements obtained through collaborations among people with different background. The authors have been carrying out collaborations in the interdisciplinary area between art and technology. One of the authors, Naoko Tosa, is well known media artist who has been active in introducing technologies into media art and interactive art she has created. On the other side other two co-authors, Jong-Il Park and Ryohei Nakatsu, are researchers in the area of communication engineering and have been eager to integrate contents and technologies.

They started their collaboration when they were colleagues at ATR (Advance Telecommunication Research Institute) in Japan in mid 1990s. At present they continue their activities in different countries, so to speak Japan, Korea, and Singapore. These counties basically have different cultures but at the same time share lots of cultures as Asian countries. Therefore based on their collaboration it is expected their collaboration could create new artworks that could fill the gap of various cultures in Asia and would express something core in the Asian culture.

Based on such basic understanding they discussed the basic concept of a video artwork the called "Four Gods Flags" that would express the birth, fight, integration, and future of various Asian cultures. Fortunately this concept was accepted by Yeosu Expo 2011 Committee. Through the creation process of about more than one year they have created the video art work which was exhibition at the expo during its open period.

This paper describes this artwork focusing the relationship between this artwork and Yeosu Expo, the concept of the artwork, and the creation process of the artwork.

\subsection{Overview of Yeosu Expo 2012}

\subsubsection{Yeosu Expo 2012}

The Expo is one of the world's oldest and largest international events sponsored by BIE (Beaurou International des Expositions). There are two types of Expos. One is the International Registered Exhibition (World Expo) which takes place every five years and lasts for six months. The World Expo is characterized by the broad scope of the chosen theme, which must be of universal concern to all of humanity. On the other hand International Recognized Exhibition (International Expo) is held between two World Expos and its duration is three months. The theme of the International Expo must represent, as with the World Expo, a global concern but it must be more specialized in its scope. For both Expos participants include states, international organizations, civil society groups, corporations, and citizens. 
Yeosu Expo is one of International Expos and was held at New Port area in Yeosu, Korea from 12 May 2012 until 12 August 2012 for three months. The site of 2,710,000 m2 consists of exhibition area of $250,000 \mathrm{~m} 2$ and auxiliary facilities. The site has the geographical edge that comes from being adjacent to the ocean, and thus, is ideal for realizing the Expo theme, "The Living Ocean and Coast." The site overlooks Hallyeosdo Marine National Park and Odong Island, and is surrounded by 317 islets, having the perfect natural conditions to make the Expo's theme to come alive. The whole view of Yeosu Expo is shown in Figure 8.1.

\subsubsection{Expo Digital Gallery}

Expo Digital Gallery (EDG) is one of the key architectures of the Expo. A large LED screen is installed on the ceiling on the passageway of the International Pavilion and is called EDG. The screen is 218 meters long and 30 meters wide which is 6,324 units of 60 inches TVs combined together. At the EDG several video works including our artwork were displayed.

Unlike other pavilions, it is not necessary for visitors to wait in a long line to watch the EDG, but they can simply look us and see the screen while walking and therefore EDG gathered a lot of attentions during the Expo. The view of EDG and international pavilions are shown in the left side of Figure 8.2. Also the right side of Figure 8.2 illustrates how EDG looks like.

\subsubsection{The process of the selection}

The construction company, GL, announced an open call for proposals the contents to be exhibited at EDG. Various persons and organization submitted their proposals and after their review our proposal on "Four Gods Flags" has been selected as one of video works to be exhibited at EDG during the Expo.

\subsection{Concept of "Four God Flags"}

From the ancient time both in Korea, China, and Japan, there has been a legend that four sacred beasts or four gods exist in four directions protecting people. These four gods are; the blue dragon of the east, the white tiger of the west, the red phoenix of the south, and the black turtle-snake of the south.

This idea has been related to the concept of "feng sui." Good fen sui is realized at a place with mountains in the back and water in the front, such as Yeosu city. It has been said that a place with good feng sui is well protected by the four gods.

In the Expo Digital Gallery, a main street of the 2012 Yeosu Expo, the images of these four gods will be shown in a huge ceiling LED display with the size of $218 \mathrm{~m} \times 30 \mathrm{~m}$ and appealing their dynamic movements to the audience. 
The background images express underwater scenes with traditional Asian landscape taste. This is based on the idea of integrating traditional Asian culture and the ocean, that is the main theme of the Expo.

At the same time as Expo would be an occasion to show people the vision of our future world. We tried to express how knowledge and wisdom came out of old concept of the four gods and also tried to express our future where people all over the world could be united filling the gap of various cultures.

After the dynamic movements of the four gods, they are merged and is represented by the blue dragon, as 2012 is the year of dragon (Figure $8.3 \mathrm{a}, \mathrm{b}, \mathrm{c}, \mathrm{d}$ ).

Then the process of how human has progressed and obtained knowledge and wisdom throughout the long history is visualized by a group of old Chinese characters that came out of the blue dragon. These old Chinese characters gradually change into the normal Chinese characters and also change into a text (Figure 8.3. e, f).

Then we tried to express the future when people would have richer wisdom, exchange their wisdom and share their wisdom filling the gap of countries and cultures through the image that each of these characters would change into a form of Maitreya and they chat each other. Maitreya is a god that appears in the long future and is relevant to express the image of out future. And then in the final stage the images of Maitreya change into the images of the four gods to express the dynamism human should maintain even in the future regardless of their country, culture and religion (Figure 8.3. g, h).

\subsection{Creation Process}

\subsubsection{Four Gods of Goguryeo Tombs and animation}

Four gods that are depicted on the ceiling of Goguryeo ancient tomb were used to express their resurrection. The video begins with a scene that these Gods begin to move slowly, directing the movement was solemn. The animation was created with hand-drawn images of all the keyframes, then with morphin

\subsubsection{Dragon with Korean pattern}

Dragon is a sacred animal commonly used in Asian countries. we created the dragon image so that it looks like a dragon in Korea. It has big eyes, a feature of the Korean dragon, and its face is not thin like the Japanese dragon. As there are various beautiful patterns of dragon designs in South Korea, these patterns were attached to the body of the dragon it. It is very effective and you will see a very beautiful scene of dragon' swimming underwater (Figure 8.5).

\subsubsection{Background Sansui image and oracle bone script animation}


As the theme of the Expo was "sea," we have created a background landscape image expressing an ocean. The landscape image itself is an animetion which we created showing the old story of the Korean turtle that goes for a journey to get a rabbit heart for its king. In addition, the change from oracle bone scripts, which are the roots of Chinese characters, to modern Chinese characters is expressed by animation symbolizing the birth of wisdom. Then these characters change themselves into Heart Sutra symbolizing the Asian philosophy.

\subsection{Conclusion}

The created video artwork of "Four Gods Flags" was regularly exhibited with other video works the Expo Digital Gallery (EDG) of Yeosu Expo 2012 from mid May 2012 until mid August and gathered lots of attentions and interest from visitors of the Expo. Especially our artwork was recognized as the most distinguished one among the video works exhibited at EDG. Based on our contribution to the Expo, one of the authors of this paper, Naoko Tosa, was awarded by Yeosu Expo Committee.

\section{Conclusion}

In this chapter the relationship among entertainment, culture, and art was treated. As entertainment, especially digital entertainment has been usually understood to mean games, it has been seldom that entertainment has been discussed in relation with culture and art. Therefore the positioning of this chapter is unique in this handbook and is vulnerable.

Firstly entertainment was discussed by higher point of view and was concluded that from its origin entertainment is an essential part of human mental sustainability and therefore should have a close relationship with culture and art.

Then the relationship between culture and technology was discussed and a new interdisciplinary research area of Cultural Computing was proposed where computers treat various cultural issues. Then three examples of Cultural Computing research were described to some details so that readers could understand how actually computers can handle cultural issues. Also by reading these three examples of Cultural Computing readers would understand how differently cultural issues are treated in East and West. At the same time, however, it is expected that readers would notice that there are mutual similarities of basic concepts as well as computing methodologies among these three different systems. Most notable similarity is that interactions and dialogues between these systems and users do not aim to give the users right answers that have been memorized in the systems. Instead, through the interactions all of these systems try to confuse the users, make them to confront their own self, and expect that the users would 
find out their own self after their experience. This means that Cultural Computing could provide totally different experiences to people from those conventional user-computer interaction could provide.

Then as the next step the relationship between culture and media art wad discussed. As a first step the definition and history of media art was described making it clear that technologies are closely connected with media art and technologies play an essential role in media art. At the same time it was pointed out that futuristic and material-oriented nature of technologies, it has been seldom that cultural issues are treated in media art. As the original relationship between culture and art was tight, however, it was pointed out that media art should treat cultural issues for its sustainability. One good example of media art that treats cultural issues is described to show how media art and cultural issues could be integrated.

\section{References}

ACM. (2000) SIGGRAPH 2000 Conference Proceedings: Computer Graphics Annual Conference Series. A Common Sense Media Research Study. (2012) Social Media, Social Life: How Teens View Their Digital Lives,

Alisi TM, D'Amico G, Ferracani A, Landucci L, Torpei N. (2010) Natural interaction for cultural heritage: the archaeological site of Shawbak. In Proceedings of the International Conference on Multimedia (MM '10), pp.1449-1452, ACM New York, USA, 2010

Artese MT, Gagliardi I. (2012) Cataloging intangible cultural heritage on the web. EuroMed'12: Proceedings of the 4th international conference on Progress in Cultural Heritage, Springer LNCS 7616 pp.676-683, Springer Berlin Heidelberg.

Ascott R (2003) Telematic Embrace: Visionary Theories of Art, Technology, and Consciousness. University of California Press.

Balazs B. (1970) Theory of the Film: Character and Grows of a New Art. Dover Publications.

Bartneck C, Hu J, Salem B, Cristescu R, Rauterberg M. (2008) Applying Virtual and Augmented Reality in Cultural Computing. International Joural of Virtual Reality, Vol. 7, No. 2, pp. 11-18.

Bell G. (2004) The age of auspicious computing? Interactions, Vol.11, No.5, pp.76-77.

Bell G. (2006) No more SMS from Jesus: ubicomp, religion and techno-spiritual practices. UbiComp'06 Proceedings of the 8th international conference on Ubiquitous Computing, Springer LNCS 4206, pp.141-158, Berlin, Springer Berlin Heidelberg.

Benton JR, DiYanni RJ. (2011) Art and Culture: An Introduction to the Humanities, Combined Volume. Pearson. 
Betancourt M. (2006) Thomas Wilfred' Clavilux, Wildside Press.

Buie E, Blythe M. (2013) Spirituality: there's an app for that! (but not a lot of research). In CHI '13 Extended Abstracts on Human Factors in Computing Systems on - CHI EA '13, pp.2315-2324, ACM New York, USA.

Cameron F, Kenderdine S. (2007) Theorizing Digital Cultural Heritage: ACritical Discourse, Volume 59 of Media in transition. MIT Press.

Candy L, Edmonds EA. (2002) Explorations in art and technology, Springer.

Carroll L. (1865) Alice's adventures in Wonderland. Macmillan, London.

Choi W, Fukumori T, Furukawa K, Hachimura K, Nishiura T, and Yano K. (2010) Virtual Yamahoko parade in virtual Kyoto. In ACM SIGGRAPH 2010 Posters on - SIGGRAPH '10, page Article No.146, ACM New York, USA.

Choudary O, Charvillat V, Grigoras R, Gurdjos P. (2009) MARCH: mobile augmented reality for cultural heritage. In Proceedings of the 17th ACM international conference on Multimedia, Vol. 3, pp.1023-1024. ACM New York, USA.

De Bary WMT. (1996) Confucian Education in Premodern East Asia. in Tu Wei-ming ed.,Confucian Traditions in East Asian Modernity, Massachesetts: Harvard University Press, pp. 21-38.

Dutta S, Mia I. (2009) The Global Information Technology Report 2008-2009. World Economic Forum, Geneva.

Eriksen TH. (2001) Between Universalism and Relatvism: A Critique of the UNESCO Concept of Culture, in Cowan JK et al. eds Culture and Rights, Cambridge University Press, pp.127-

Fellbaum C. (1998) WordNet: An Electronic Lexical Database. MIT Press, Cambridge, MA.

Flaherty, M.G. (1999) A Watched Pot: How We Experience Time. New York, NY: New York University Press.

Fogg BJ. (2003) Persuasive Technology: Using Computers to Change What We Think and Do.

Amsterdam, The Netherlands; Boston, MA: Morgan Kaufmann Publishers.

Fraisse P. (1984) Perception and estimation of time. Annual Review of Psychology, Vol. 35, pp.1-36.

Gallagher S, Shear, J. (Eds) (2000) Models of the Self. Exeter, UK, Imprint Academic.

Gaver W, Blythe M, Boucher A, Jarvis N, Bowers J, Wright P. (2010) The prayer companion: openness and speci_city, materiality and spirituality. In Proceedings of the 28th international conference on Human factors in computing systems - CHI '10, pp.2055-2064, ACM New York.

Glicksohn J. (1992) Subjective time estimation in altered sensory environments. Environment and Behavior, Vol. 24, pp.634-652.

Greenberg C. (1971) Art and Culture: Critical Essays. Beacon Press 
Greenwald AG, McGhee DE, Schwartz JKL. (1998) Measuring individual differences in implicit cognition: the implicit association test. Journal of Personality and Social Psychology, Vol. 74, pp.14641480.

Greenwald AG, Farnham SD. (2000) Using the implicit association test to measure self-esteem and self-concept. Journal of Personality and Social Psychology, Vol. 79, pp.1022-1038.

Heiligman D. (1996) From Caterpillar to Butterfly. New York, NY: Harper Collins.

Higgins Dic, Vostell W. (1971) Fantastic Architecture. Something Else Press.

Hiyama A, Doyama Y, Miyashita M, Ebuchi E, Seki M, and Hirose M. (2011) Wearable display system for handing down intangible cultural heritage. In Proceedings of the 2011 international conference on Virtual and mixed reality: systems and applications - Volume Part II, pp.158-166. Springer-Verlag.

Hlubinka M, Beaudin J, Tapia EM, John S. (2002) An AltarNation: interface design for meditative communities. In CHI '02 extended abstracts on Human factors in computing systems - CHI '02, pages 612\{613, ACM New York, USA.

Hu J, Bartneck C. (2005) Culture matters - a study on presence in an interactive movie, Proceedings of the 8th Annual International Workshop on Presence, London, pp.153-159.

Hu j, Bartneck, C, Salem B, Rauterberg M. (2008) ALICE's adventures in Cultural Computing. International Journal of Arts and Technology, Vol.1, No.1, pp.102-118.

Huang Z, Thint M, Qin Z. (2008) Question classification using head words and their hypernyms. Proceedings of the Conference on Empirical Methods in Natural Language Processing, Association for Computational Linguistics, Morristown, NJ, USA, pp. 927-936.

Isbister K, Nakanishi H, Ishida T, Nass C. (2000) Helper Agent: Designing Assistant for Human-Human Interaction in a Virtual Meeting Space. In CHI Letters, Vol. 2, No.1. pp.57-64ACM Press, New York.

Jones CA, Aming B, Briand M, MITLCA Center. (2006) Sensorium: embodied experience, technology, and contemporary art

Juul J. (2012) A Casual Revolution: Reinventing Video Games and Their Players. The MIT Press, Boston.

Kant I. (1784). Beantwortung der Frage: Was ist Aufklärung? Berlinische Monatschrift, vol. 2, pp.481-494.

Khoo ET, Cheok AD, Liu W, Hu X, Marini P, Saksen V, Jiang J, Duh BL (2011) Confucius Computer: Bridging Intergenerational Communication through Illogical and Cultural Computing, Virtual Reality, Vol.15, No.4, pp.239-265.

Khoo ET, Cheok A, Liu W, Hu X, Marini P. (2000) Confucius Computer: bridging intergenerational communication through illogical and cultural computing, Virtual Reality. Vol.15, pp.249-265. 
Kitayama S, Markus HR, Matsumoto H, Norasakkunkit V. (1997) Individual and collective processes in the construction of the self: self-enhancement in the United States and self-criticism in Japan. Journal of Personality and Social Psychology, Vol. 72, pp.1245-1267.

Klein D, Manning CD. (2003) Accurate unlexicalized parsing. Proceedings of the 41st Annual Meeting on Association for Computational Linguistics - ACL'03, pp.423-430.

Koller D, Frischer B, Humphreys G. (2009) Research challenges for digital archives of 3D cultural heritage models. Journal on Computing and Cultural Heritage, Vol.2, No.3, pp.1-17.

Kooijmans T, Rauterberg, G.W.M. (2006) Advice from a Caterpillar: an application for cultural computing about the self. 5th International Conference on Entertainment Computing (ICEC), pp.5-8, Sanda.

Kroeber AL, Kluckhohn C. (1952). Culture: A Critical Review of Concepts and Definitions. Peabody Museum, Cambridge, Massachusetts.

Lee SK, Rennert S. (2011) Nam June Paik. Tate.

Leeman F. (1976) Hidden Images: Games of Perception, Anamorphic Art, Illusion from the Renaissance to the Present, Harry N. Abrams Inc. (1976).

Lessiter J, Freeman J, Keogh E, Davidoff J. (2001) A cross-media presence questionnaire: the ITC sense of presence inventory. Presence: Teleoperators and Virtual Environments, Vol. 10, pp.282-297.

Levoy M, Ginsberg J, Shade J, Fulk D, Pulli K, Curless B, Rusinkiewicz S, Koller D, Pereira L, Ginzton M, Anderson S, Davis J. (2000) The digital Michelangelo project. In Proceedings of the 27th annual conference on Computer graphics and interactive techniques - SIGGRAPH '00, pp.131-144, ACM Press.

Liu Y, Davis, P. (2000) Dual synchronization of chaos. Physical Review E, Vo.61, pp.2176-2179.

Lough GC. (1983) Alice in Wonderland and cognitive development: teaching with examples. Journal of Adolescence, Vol.6, No.4, pp.305-315.

Mallik A, Chaudhury S, Ghosh H. (2011) Nrityakosha: Preserving the Intangible Heritage of Indian

Classical Dance. Journal on Computing and Cultural Heritage, Vol.4, No.3, pp.1-25.

Marc L, et al. The Digital Michelangelo Project: 3D Scanning of Large Statues. Proceedings of SIGGRAPH 2000/, pp. 131-144, August 2000.

Matsuoka S, (2001) Editorial Science of Intelligence. Asahi Shimbunsha (in Japanese).

Matsuoka S. (2003) Philosophy of Sansui. Gogatsu Shobo (in Japanese)

Matsuoka S. (2004) Science of Flower, Birds, and Moon. Chuko Bunko (in Japanese).

McLuhan M, Powers BR. (1992) The Global Village: Transformations in World Life and Media in the 21st Century. Oxford University Press.

McLuhan M (2011) The Gutenberg Galaxy. University of Toronto Press. 
Murray JH. (1998) Hamlet on the Holodeck: The Future of Narrative in Cyberspace. The MIT Press.

Nakatsu N. (1998) Image/Speech Processing Adopting an Artistic Approach - Toward Integration of Art and Technology. in Art@Science Springer-Verlag, Wein New York, pp. 38-49.

Nakatsu R. (2002) Integration of Multimedia and Art for New Human-Computer Communications. PRICAI 2002: Trends in Artificial Intelligence, Springer, pp.19-28.

Nakatsu R, Rauterberg M, Vorder P. (2005) A New Framework for Entertainment Computing: From Passive to Active Experience. Entertainment Computing - ICEC2005, Springer LNCS 3711, pp.1-12.

Nakatsu R, Rauterberg M, Salem B. (2006) Forms and Theories of Communication: From Multimedia to Kansei Mediation, Multimedia Systems, Vol.11, No.3, pp.304-312.

Nakatsu R. (2009) Logos, Pathos, and Entertainment, Culture and Computing, Springer LNCS 6295, pp.137-1465.

Nakatsu R, Edirisinghe C. (2011) The Role of Movies and Telephony in the History of Communication Media. Entertainment Computing - ICEC2011, Springer LNCS 6972, pp.448-451.

Nakaya T, Yano K, Isoda Y, Kawasumi T. (2010) Virtual Kyoto Project: Digital Diorama of the Past, Present, and Future of the Historical City of Kyoto. In Toru Ishida, editor, Culture and Computing, LNCS 6259, pp.173-187, Springer-Verlag Berlin Heidelberg.

Newstead SE, Thompson VA, Handley SJ. (2002) Generating alternatives: a key component in human reasoning?. Memory and Cognition, Vol. 30, pp.129-137.

Nielsen Study. (2009) How Teens Use Media.

Nisbett RE, Peng K, Choi I, Norenzayan A. (2001) Culture and Systems of Thought: Holistic Versus Analytic Cognition. Psychological Review, Vol.108, No.2, pp.291-310.

Nisbett RE, and Masuda T. (2003) Culture and point of view. Paper presented in the Proceedings of the National Academy of Sciences, Vol. 10019, pp.11163-11170.

Okada Y, Shoji T. (2010) Digital Conservation of Cultural Assets. In Culture and Computing, LNCS 6259, pp.147-, Springer-Verlag Berlin Heidelberg.

Pavlov R, Paneva-Marinova D, Rangochev K, Goynov M, Luchev D. (2010) Towards online accessibility of valuable phenomena of the Bulgarian Folklore Heritage. In Proceedings of the 11th International Conference on Computer Systems and Technologies and Workshop for PhD Students in Computing on International Conference on Computer Systems and Technologies - CompSysTech '10, pp.329-334, ACM New York, USA, 2010.

Pedersen T. (2004) WordNet:: Similarity - Measuring the Relatedness of Concepts. Proceedings of the Nineteenth National Conference on Artificial Intelligence (AAAI-04), San Jose, CA, pp. 1024-1025. 
Pedersen T, Kolhatkar V. (2009) WordNet:: SenseRelate:: AllWords: a broad coverage word sense tagger that maximizes semantic relatedness. Proceedings of the North American Chapter of the Association for Computational Linguistics - Human Language Technologies 2009 Conference, Association for Computational Linguistics, Boulder, CO., pp. 17-20.

Pierce JS, Pausch R, Sturgill CB, Christiansen KD. (1999) Designing a successful HMD-based experience. Presence, Vol.8, No.4, pp.469-473.

Plate SB. (2002) Religion, Art, and Visual Culture: A Cross-Cultural Reader. Palgrave Macmillan.

Rauterberg M. (2004) Positive effects of entertainment technology on human behaviour. In: R. Jacquart ed., Building the Information Society, pp.51-58, IFIP, Kluwer Academic Press.

Rauterberg M. (2006) From Personal to Cultural Computing: How to Access a Cultural Experience, in Kemper G and von Hollberg P eds, uDayIV - Information nutzbar machen., Pabst Science Publ., pp.13-21.

Saga S, Vlack K, Kajimoto H, and Tachi S. (2005) Haptic video. In ACM SIGGRAPH 2005 Emerging technologies on - SIGGRAPH '05.

Schonenberg B, Bartneck C. (2010) Mysterious machines. In Proceedings of the 5th ACM/IEEE international conference on Human-robot interaction (HRI'10), pp.349-350, ACM New York, USA.

Shanken EA. (2014) Art and Electronic Media, Phaidon Press.

Shiaw HY, Jacob RJK, and Crane GR. (2004) The 3D vase museum: a new approach to context in a digital library. In Proceedings of the 4th ACM/IEEE-CS joint conference on Digital Libraries, pp.125-134. ACM New York, USA.

Sommerer C, Mignonneau L (1999) Art as a Living System: Interactive Computer Artworks. Leonardo, Vol.32, No.3, pp.165-173.

Stavrakis E, Aristidou A, Savva M, Himona SL, Chrysanthou Y. (2012) Digitization of Cypriot folk dances. EuroMed'12 - Proceedings of the 4th international conference on Progress in Cultural Heritage Preservation, LNCS 7616, pp.404-413, Springer Berlin Heidelberg.

Stocker G, Leopoldseder H. (2914) Art Electronica Center. Edition Lammerhuber; Bilingual edition.

Shwarz HP. (1997) Media—Art—History: Media Museum, Zkm, Center for Art and Media Karlsruhe. Prestel.

Tinguely J. (1988) Jean Tinguely: A Magic Stronger Than Death. Abbeville Pr.

Torrens D, Thompson VA, Cramer, KM. (1999) Individual differences and the belief bias effect: mental models, logical necessity, and abstract reasoning. Thinking and Reasoning, Vol. 5, pp.1-28.

Tosa, N. (2000) Expression of Emotion, Unconsciousness with Art and Technology, in Hatano G, Okada N, Tanabe N eds. AFFECTIVE MINDS. ELSEVIER, pp.183-201. 
Tosa N, Matsuoka S, Miyazaki K. (2003) Interactive storytelling system using behavior-based non-verbal information: ZENetic computer. Proceedings of the Eleventh ACM International Conference on Multimedia, pp.466-467, 2003, ACM Berkeley, USA.

Tosa N, Matsuoka S, Ellis B, Ueda H, Nakatsu R. (2005) Cultural Computing with Context-Aware Application: ZENetic Computer. Entertainment Computing - ICEC2005, Springer LNCS 3711, pp.13-23. Tosa N, Matsuoka S (2006) ZENetic Computer: Exploring Japanese Culture, Leonardo, Vol.39, No.3, pp.205-211.

Tosa N, Obara H, Minoh M. (2008) Hitch haiku: An interactive supporting system for composing haiku poem. In Proceedings of the 7th international conference on Entertainment Computing (ICEC 2008), pp. $209-216$.

Tosa N. (2010) Cultural Computing - Creative Power Integrating Culture, Unconsciousness and Software. In Culture and Computing, Springer LNCS 6259, pp. 127-136.

Tosa N, Jong-Il P, Nakatsu R. (2013) Korea Expo 2012 and Its Digital Gallery Work Focusing Asian Four Gods, Culture and Computing, pp.45-50.

Tosa N. (2015) Cross-Cultural Computing: An Artist's Journey, Springer Series on Cultural Comput Tribe M, Jana R, Grosenick U. (1995) New Media Art. New Media Art, Taschen Publisher.

Tsai CC, Cai Z, Bruya B. (1996) Confucius Speaks: Words to Live By, Anchor Books.

Uriu D, Okude N, Inami M, Taketomi T, Sato C. (2012) Where Buddhism encounters entertainment computing. ACE'12 Proceedings of the 9th international conference on Advances in Computer Entertainment, Springer LNCS 7624, pp.589-592, Springer Berlin Heidelberg.

Wallace R. (2003) The elements of AIML style. Alice AI Foundation.

Wang X, Khoo ET, Fu C-R, Cheok AD, Nakatsu R (2013) Confucius Chat: Promoting Traditional Chinese Culture and Enhancing Intergenerational Communication through a Chat System (2013) Culture and Computing, pp.123-128.

Whiting J. (2005) Auguste \& Louis Lumiere: Pioneers in Cinema Film. Mitchell Lane Publishers.

Wu X, Tosa N, Nakatsu R. (2009) New Hitch Haiku : An Interactive Renku Poem Composition Supporting Tool Applied for Sightseeing. In Proceedings of the 8th international conference on Entertainment Computing (ICEC2009), pp.191-196, Springer Berlin Heidelberg.

Xu S, Jiang H, Jin T, Lau F.C.M., Pan Y. (2009) Automatic Generation of Chinese Calligraphic Writings with Style Imitation. IEEE Intelligent Systems, Vol.24, No.2, pp.44-53, March 2009.

Wyche SP, Caine KE, Davison BK, Patel SN, Arteaga M, Grinter RE. (2009) Sacred imagery in techno-spiritual design. In Proceedings of the 27th international conference on Human factors in computing systems - CHI 09, pp.55-58, ACM New York, USA. 
Yao C, Xiao J, Guo TQ, Xia L. (2010) Real-time digitized shadow play performance method based on multi-point interactive controlling method. International Journal of Computer Applications in Technology, Vol.38, No.1/2/3, pp.86-92.

Zhu K, Ranashinghe N, Edirisinghe C, Fernando ONN, Ceok AD. (2011) Poetry mix-up. Computers in Entertainment, Vol.9, No.2, ACM New York, USA. 


\section{Figures and Tables}

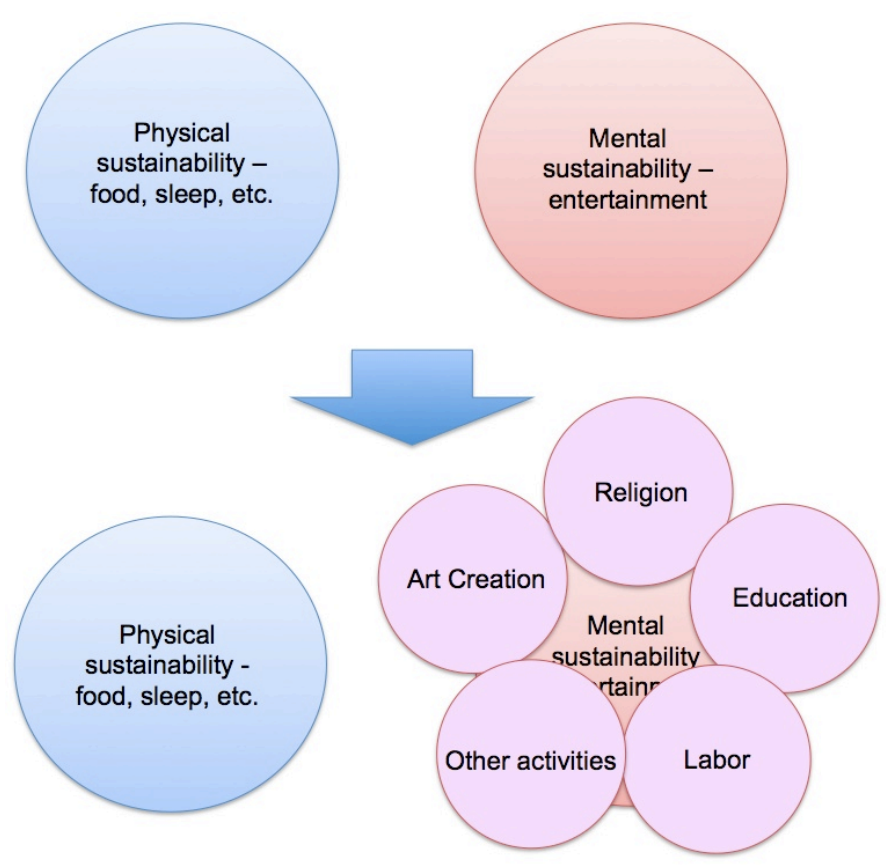

Figure 2.1 Changes in the physical and mental sustainability of human beings.

Table 4.1 Alice's adventures in six stages

\begin{tabular}{|l|l|l|l|}
\hline Stage & Theme & Experience & Measurement \\
\hline In the park & Time & Boredom and curiosity & Retrospective duration \\
\hline Down the rabbit hole & Environmental space & Disorientation & Presence \\
\hline Eat Me and Drink Me & Personal space & Shinking and growing & Presence \\
\hline The pool of tears & Genesis & Swimming, out of water & \\
\hline Advice from a catapilar & Self & Questioning the concept of self & Personality, self-esteem \\
\hline The Cheshire cat & Logic & & and -concept \\
\hline
\end{tabular}




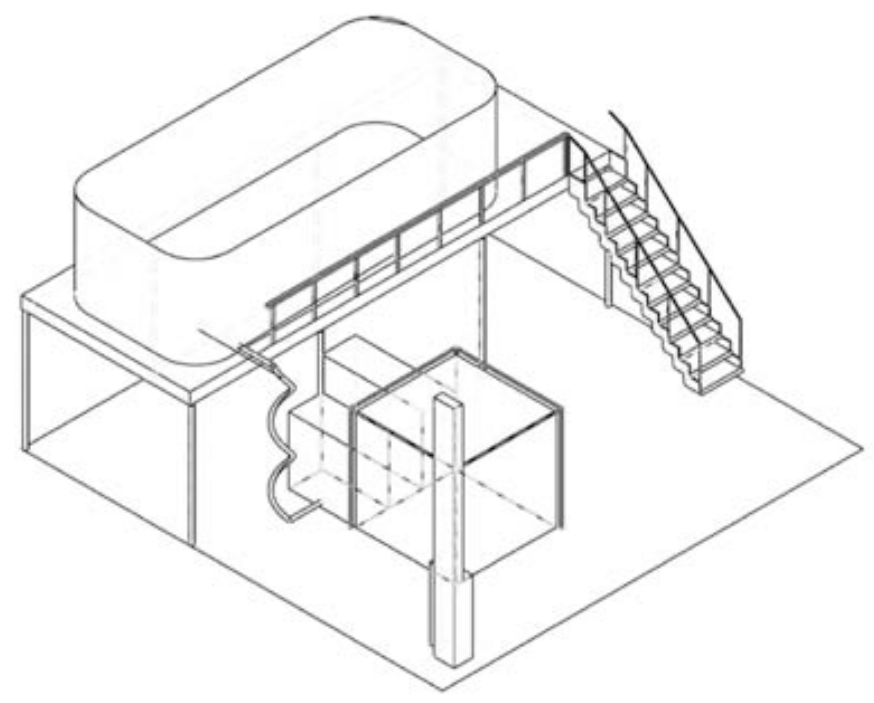

Figure 4.1 Schematic drawing of the Alice installation

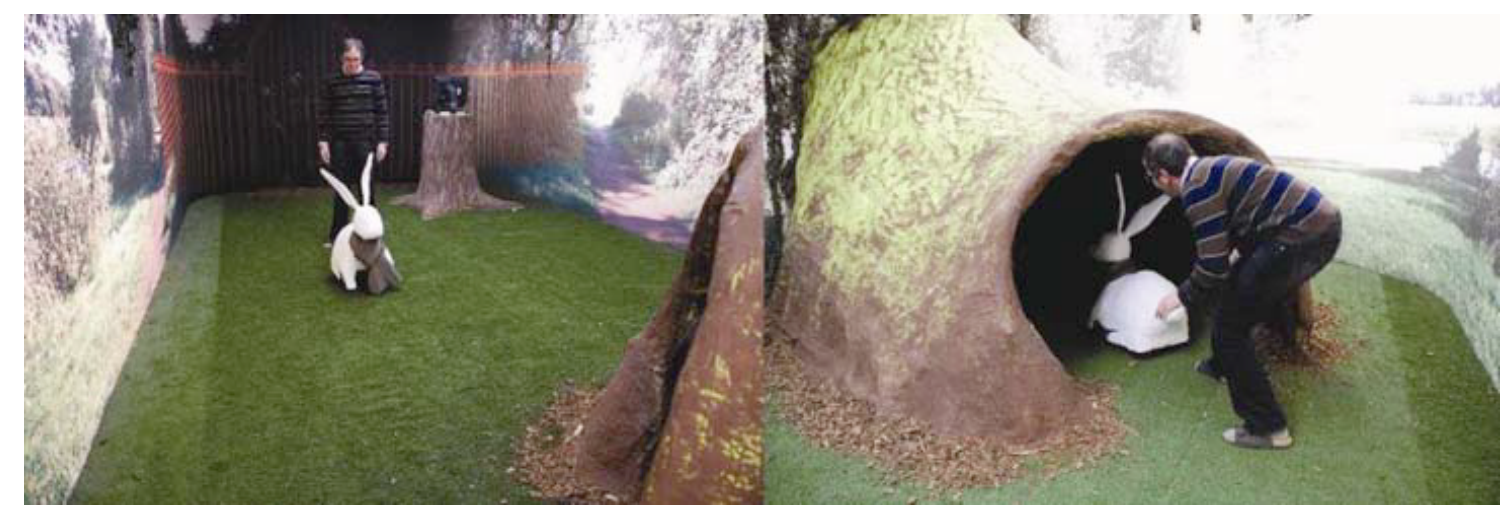

Figure 4.2 A visitor follows the rabbit

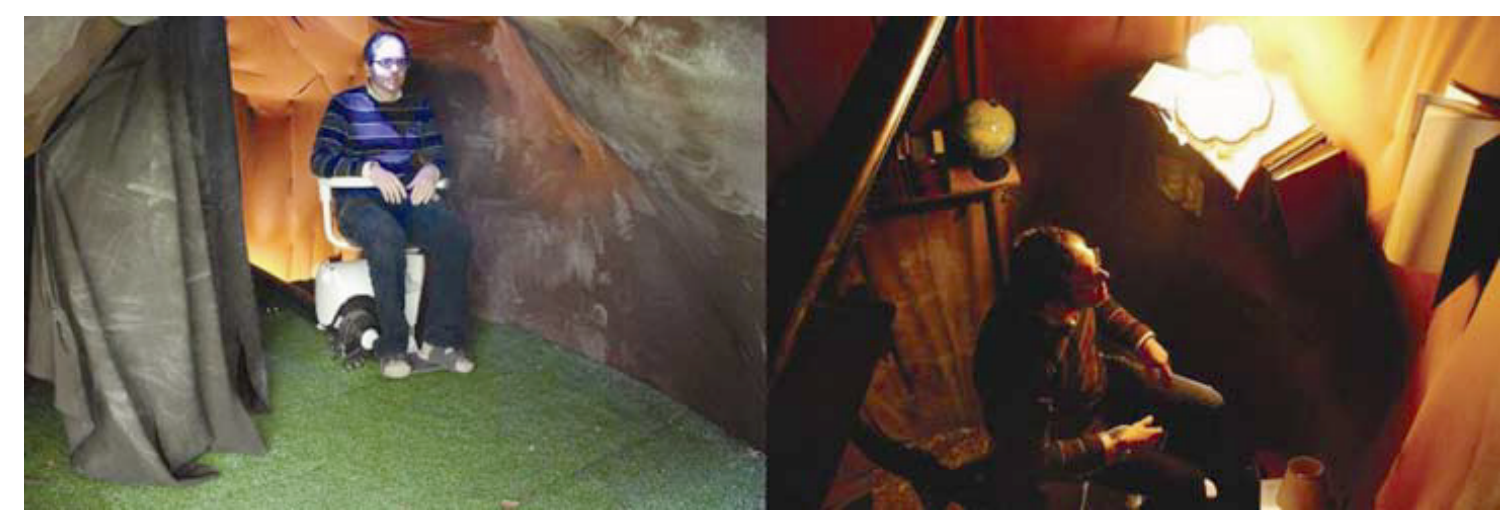

Figure 4.3 A visitor descents through the rabbit hole 


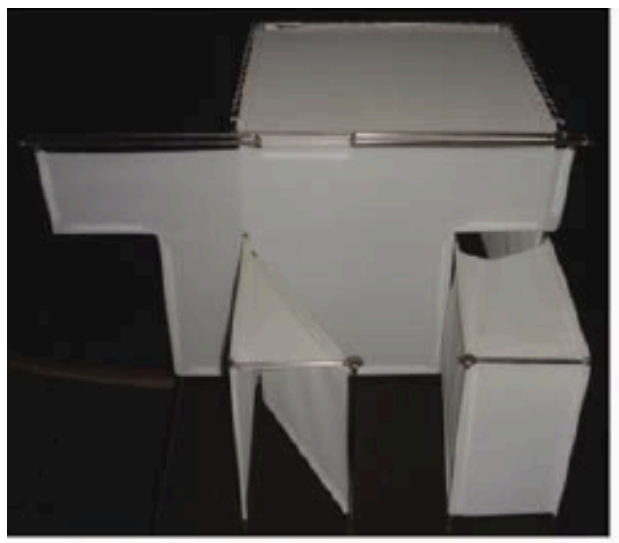

(a) entrance open

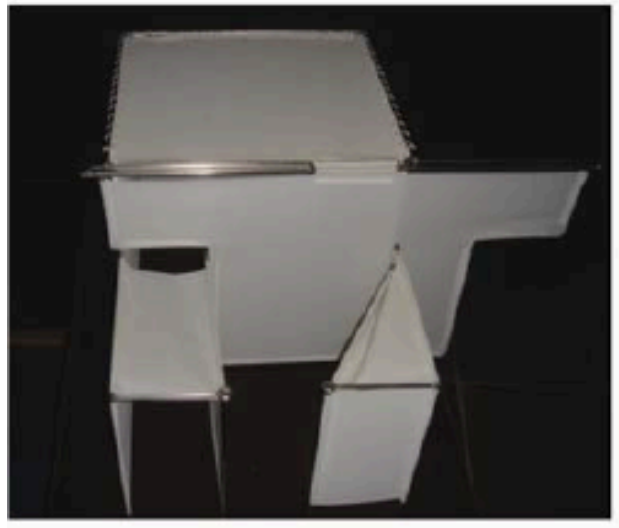

(c) exit open

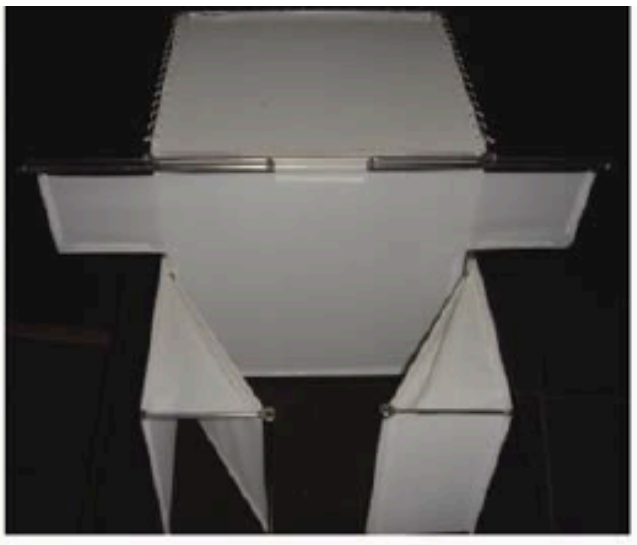

(b) both entrance and exit closed

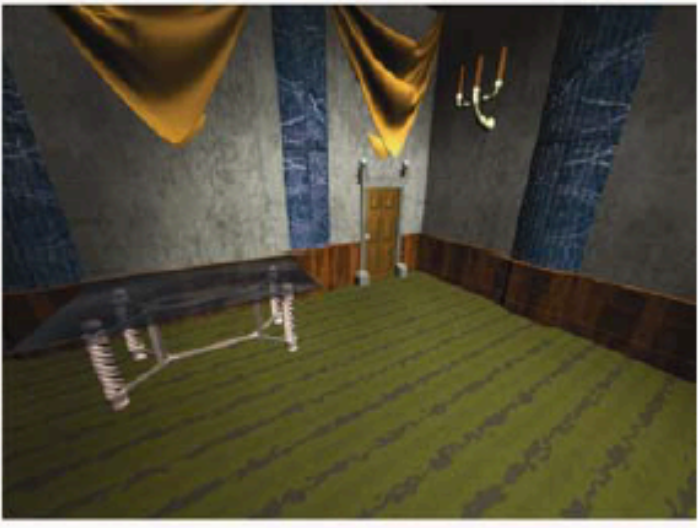

(d) Virtual room

Figure 4.4 Scale model of the CAVE (a-c) and the virtual room (d)

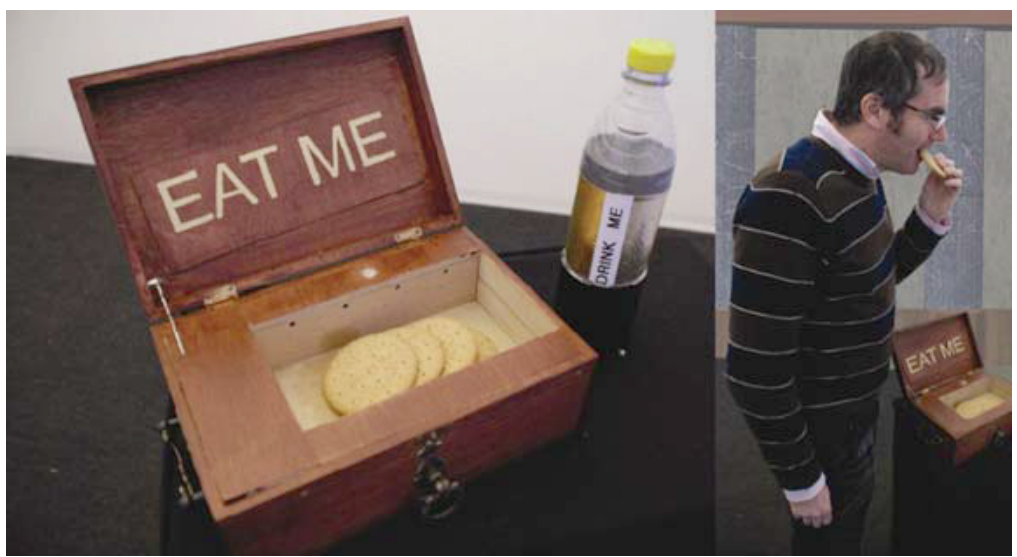

Figure 4.5 Eat Me and Drink Me (left), visitor eating the cookie (right) 


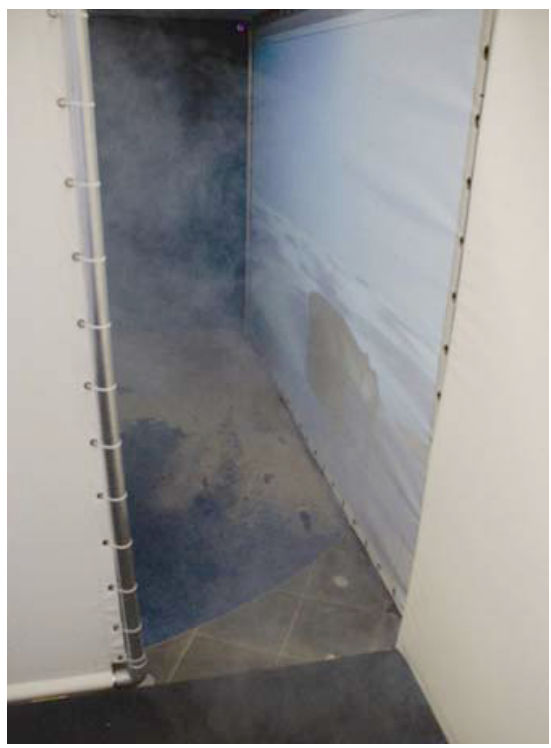

Figure 4.6 Pool of tears

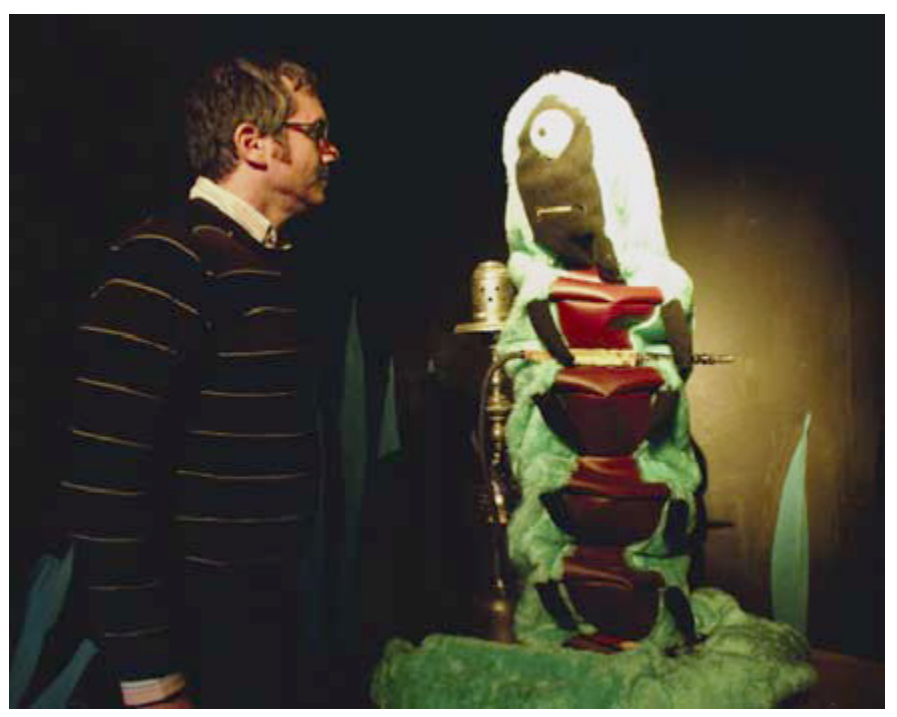

Figure 4.7 A visitor talking to the caterpillar 


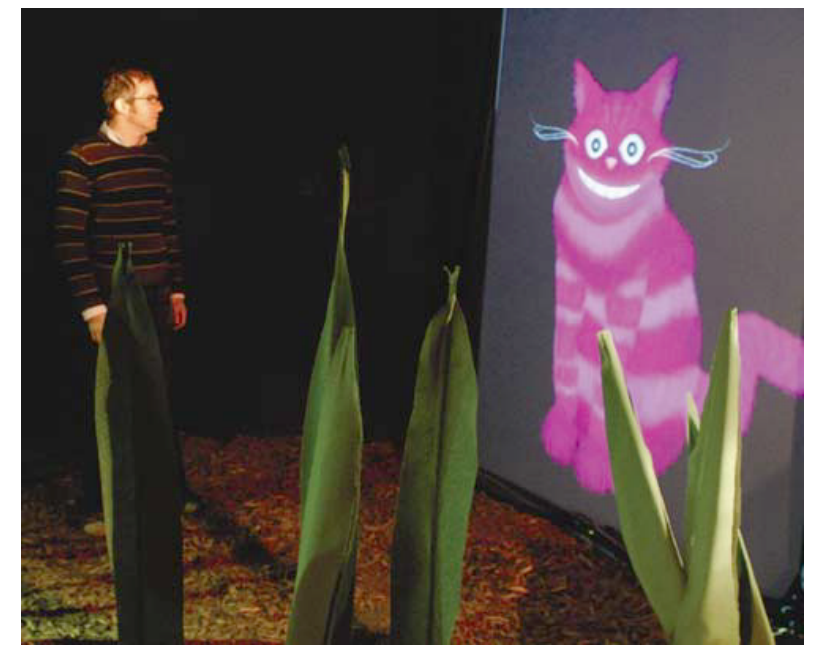

Figure 4.8 A visitor talks to the Cheshire cat

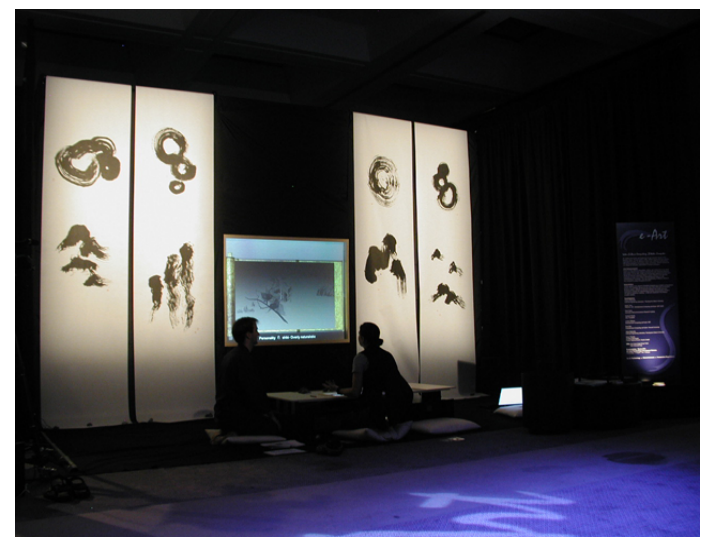

Figure 5.1 ZENetic Computer at SIGGRAPH2004 Emerging Technologies

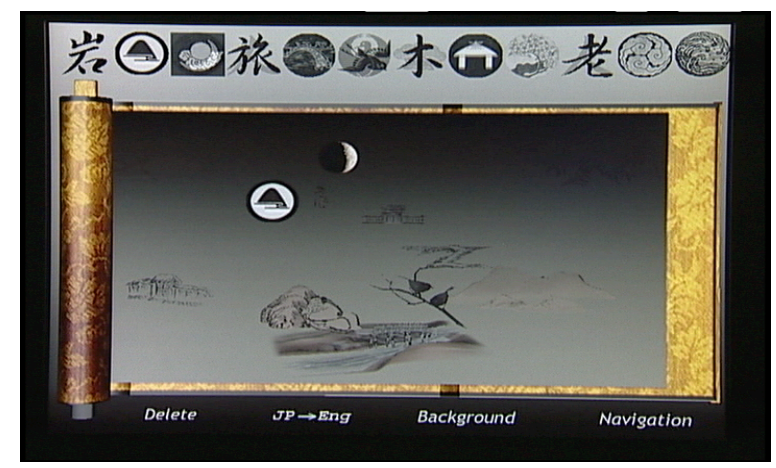

Figure 5.2 Making a 3D sansui ink painting 


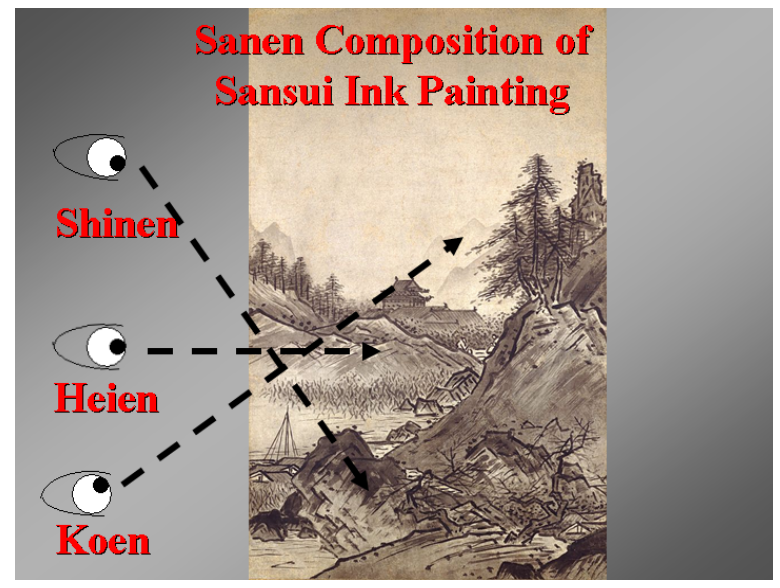

Figure 5.3 Composition of sanen perspective in Sesshu's work

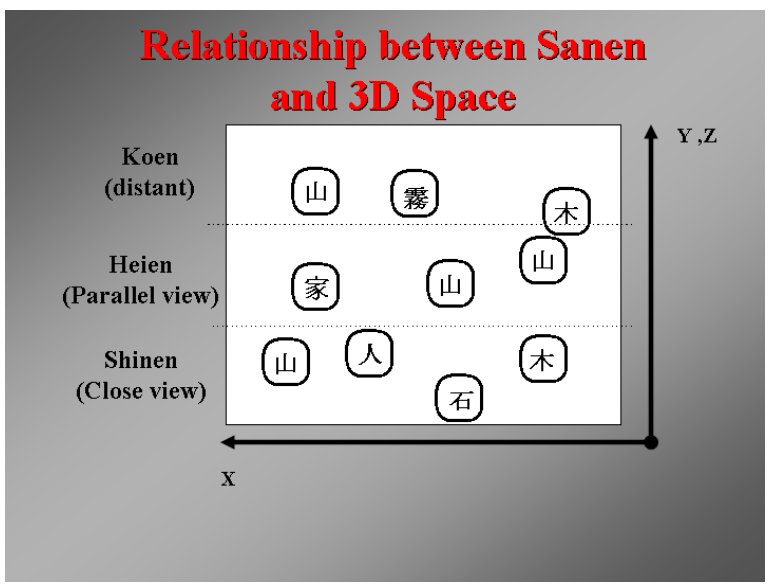

Figure 5.4 Composition and distance within 3D space

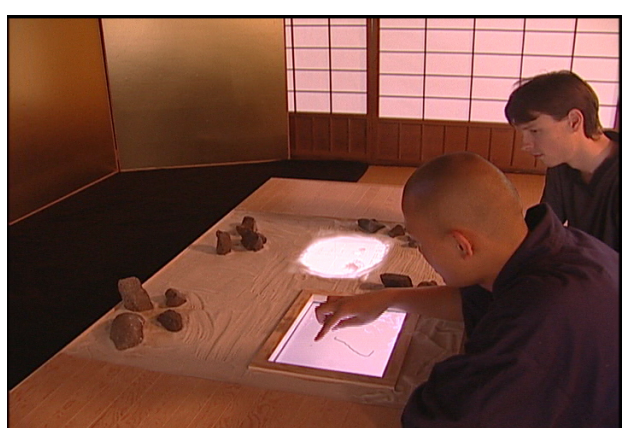

Figure 5.5 Interaction with the rock garden interface 


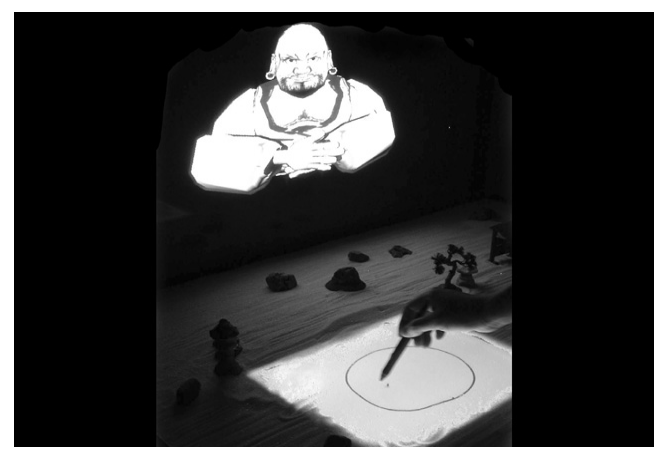

Figure 5.6 ZEN dialogue "Dharma Anjin," where the user draws herself using the touch screen

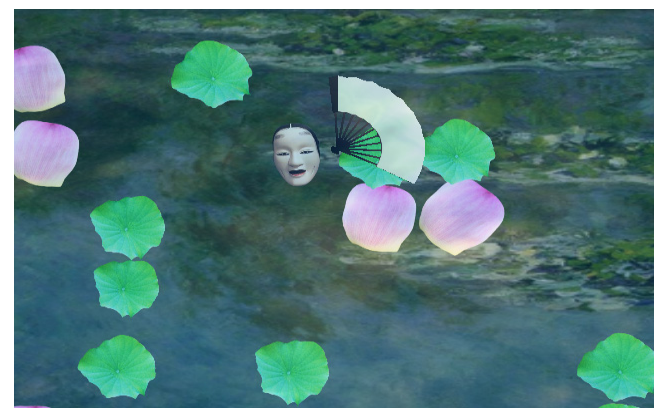

Figure 5.7 ZEN dialogue "The Lotus Smiles," where the user's goun state increases with successful matching of Noh Theater masks.

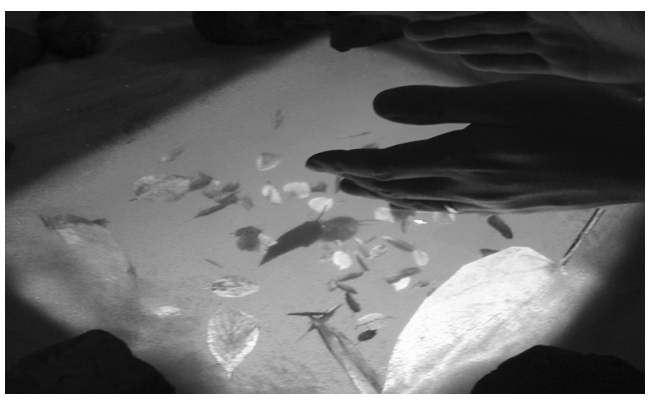

Figure 5.8 ZEN dialogue "The sound of one hand clapping" 


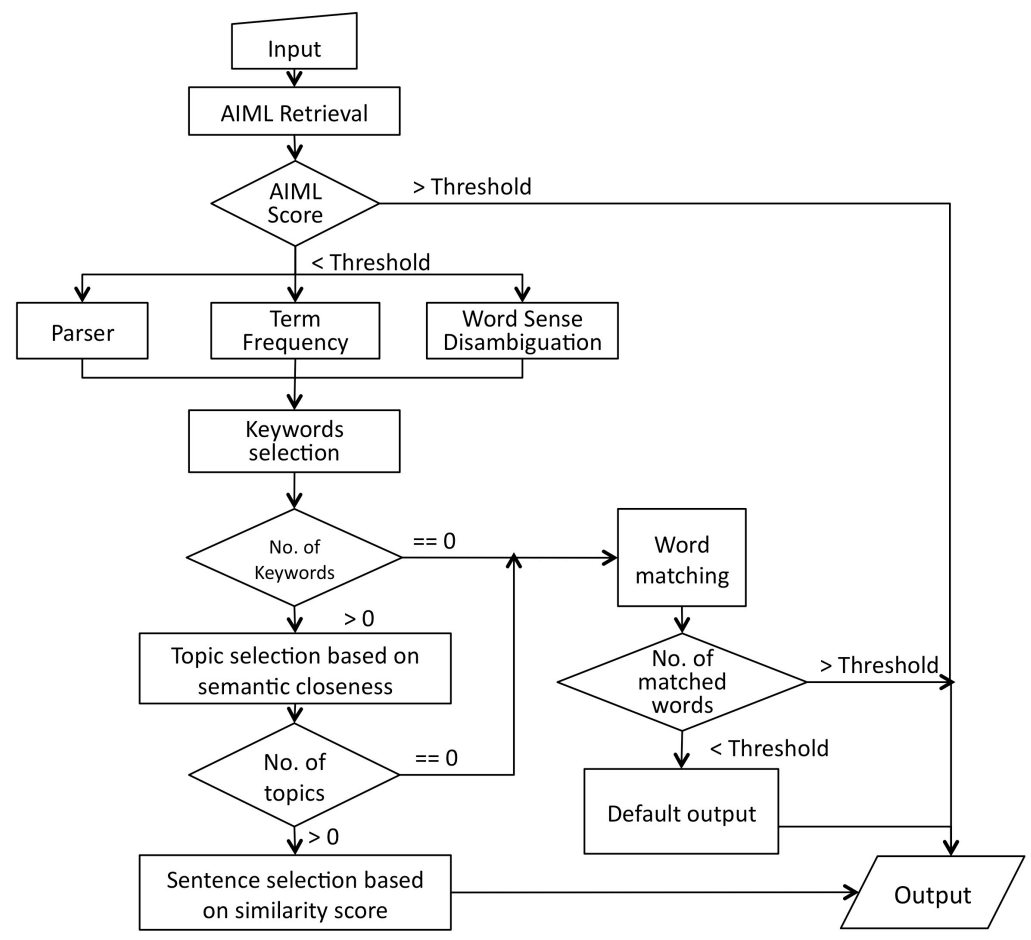

Figure 6.1 A flow chart of the iSage thinking engine

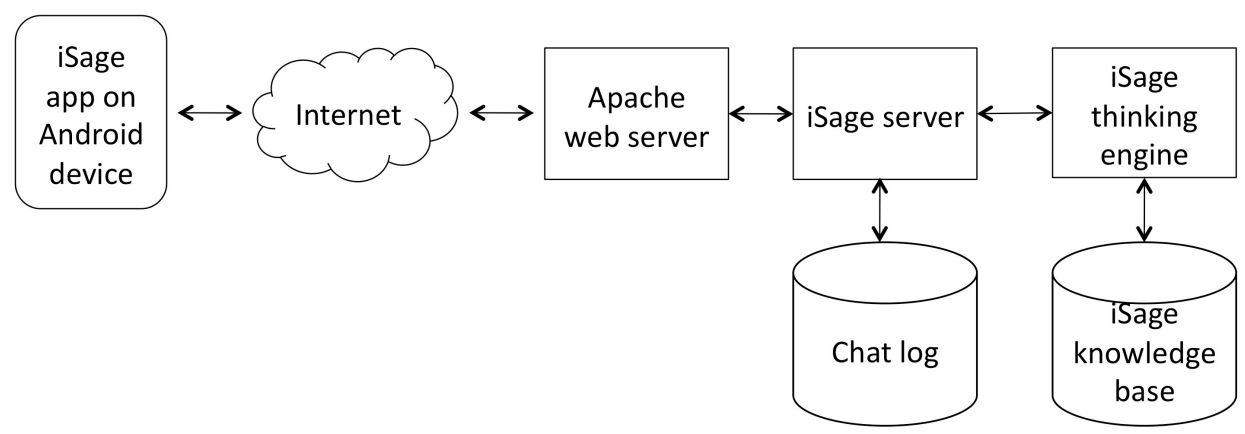

Figure 6.2 Architecture of the iSage system 


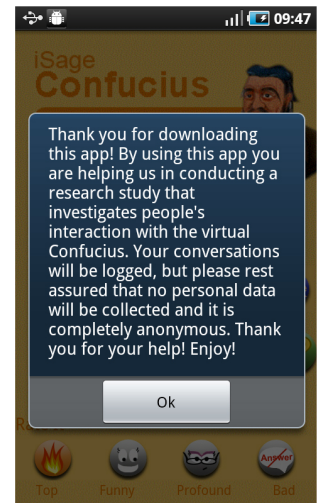

(a)

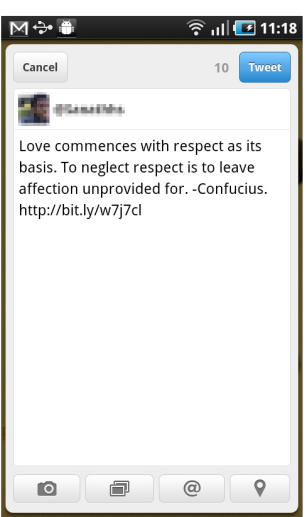

(e)

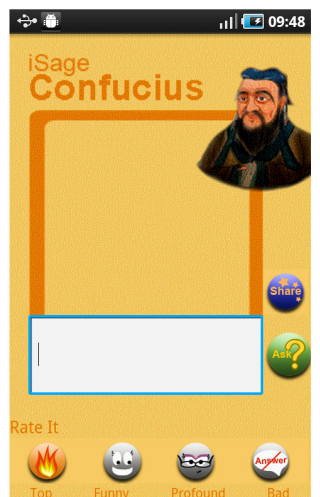

(b)

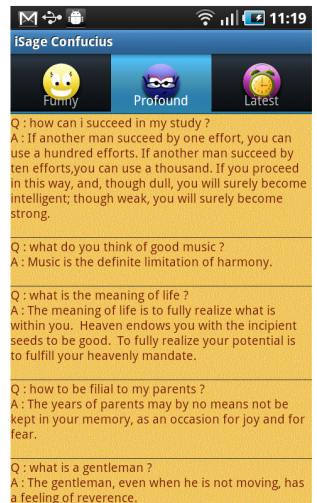

(f)

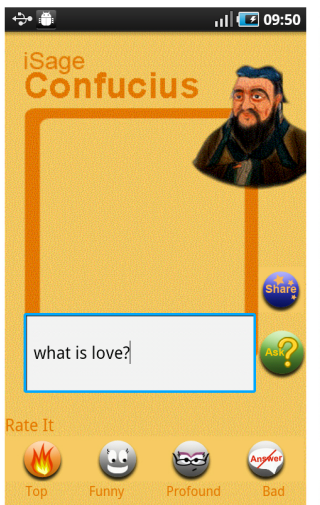

(c)

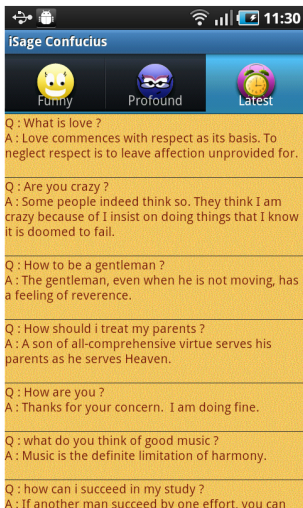

(g)

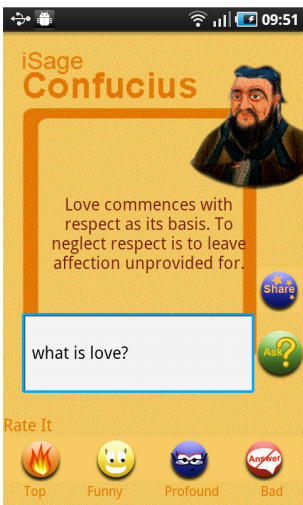

(d)

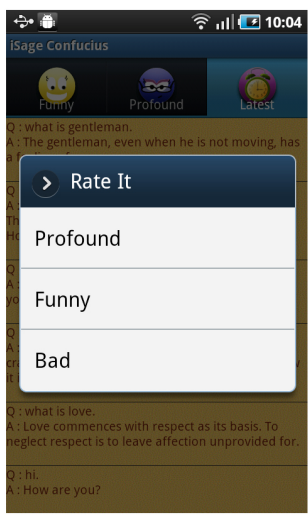

(h)

Figure 6.3 A screenshot of the iSage Confucius application

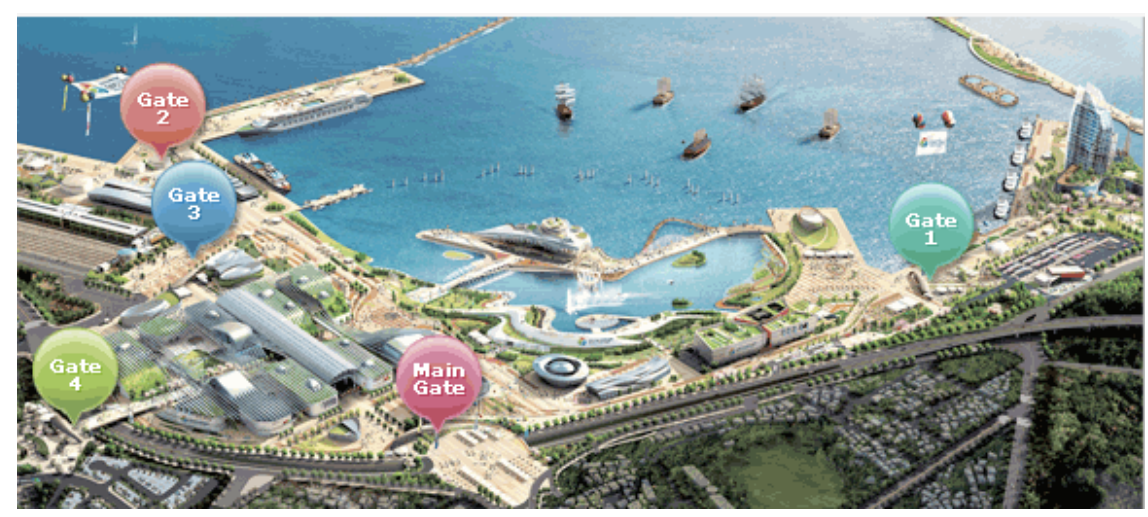

Figure 8.1 Bird view of the Yeosu Expo site. 


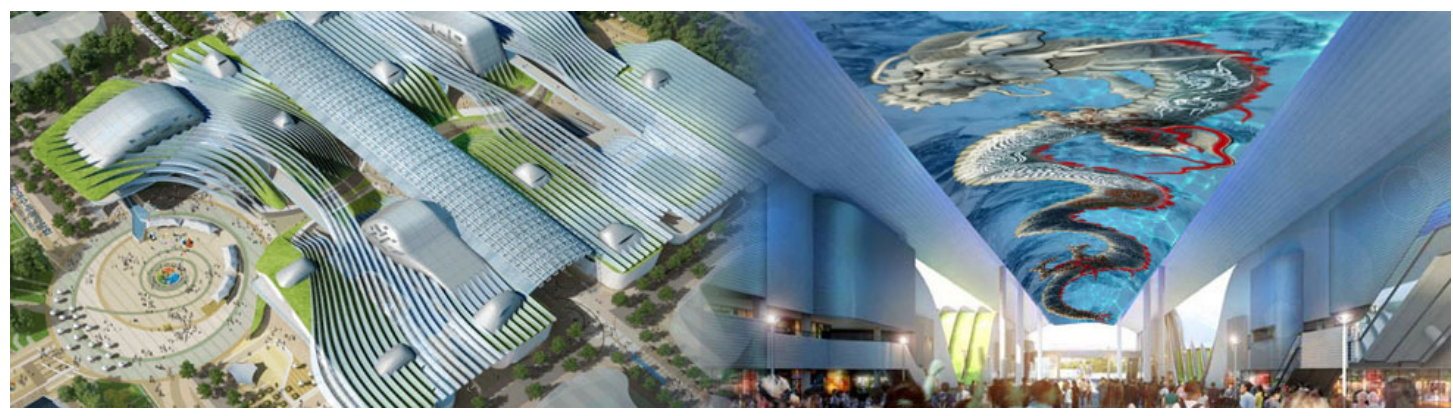

Figure 8.2 Expo Digital Gallery and its inside.

a

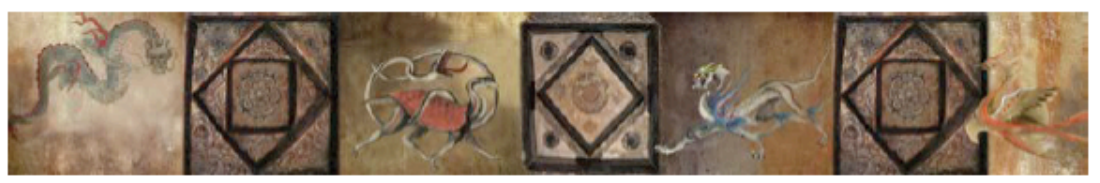

b

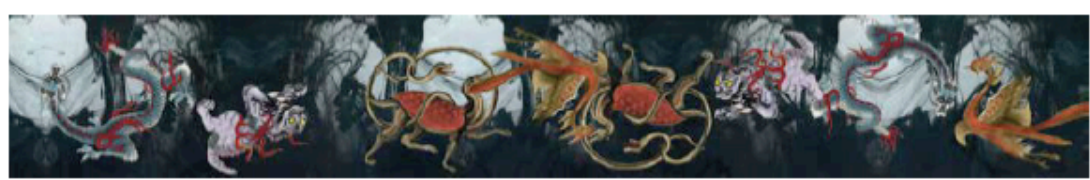

c

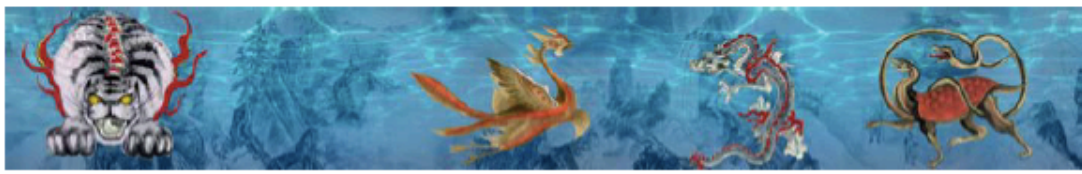

d

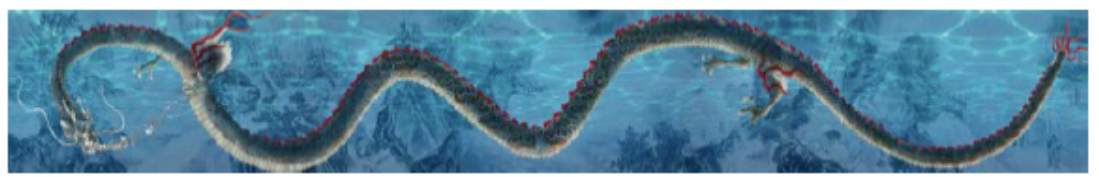

e

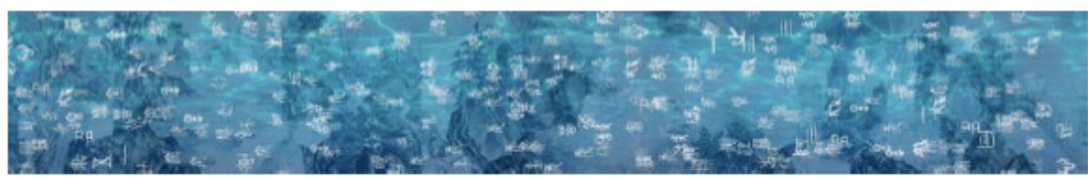

f

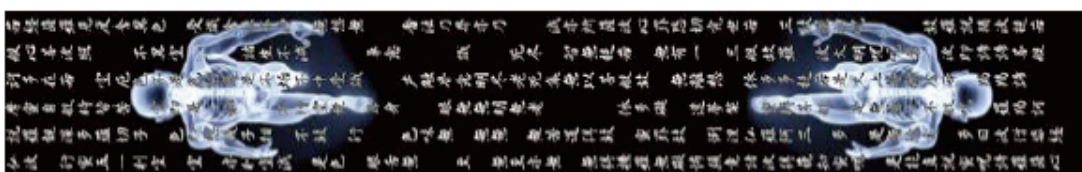

g

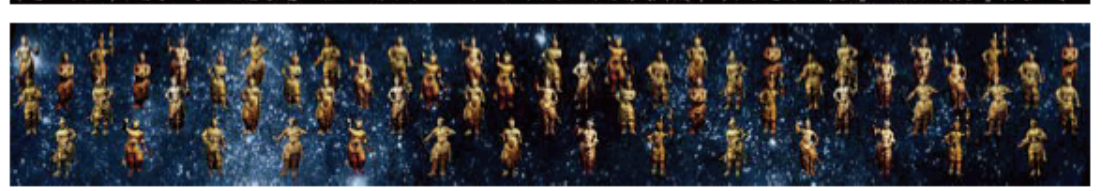

$\mathrm{h}$

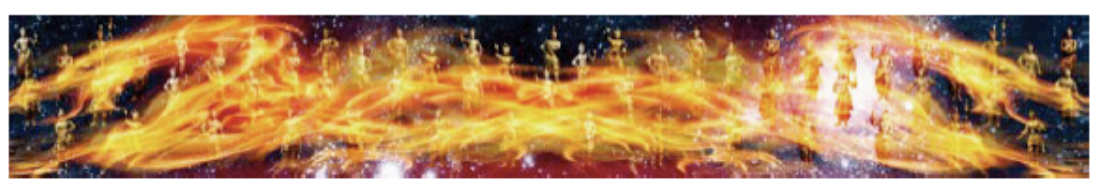

Figure 8.3 Screenshot of "Four God Frags" 


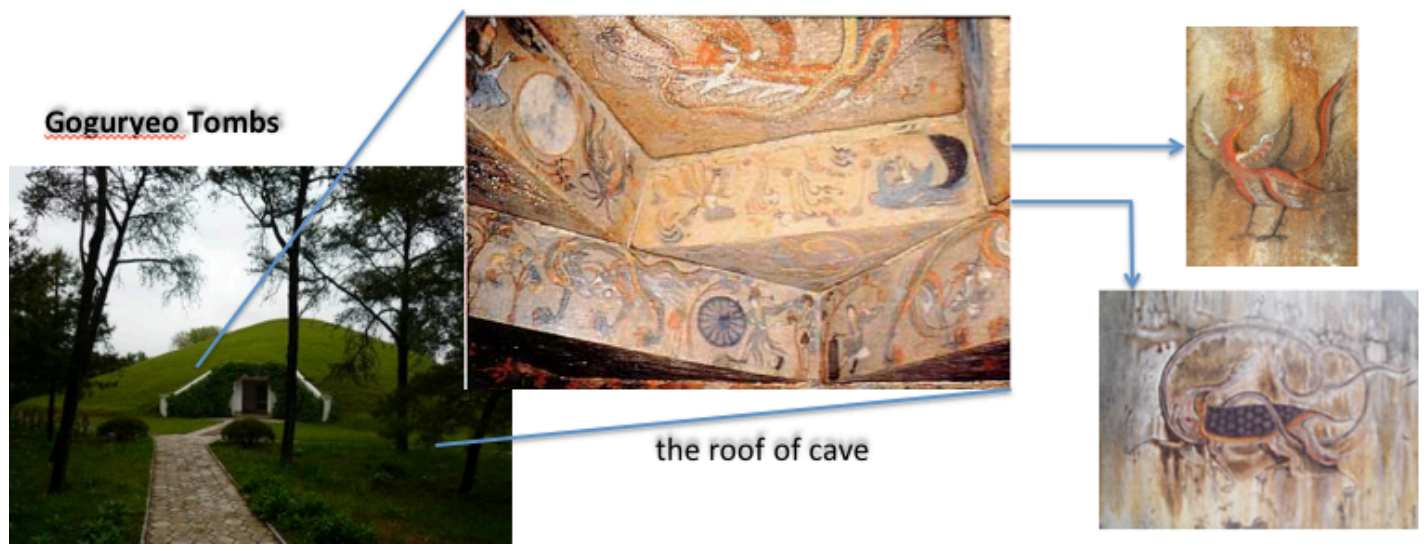

Figure 8.4 Four God of Goguryeo Tombs

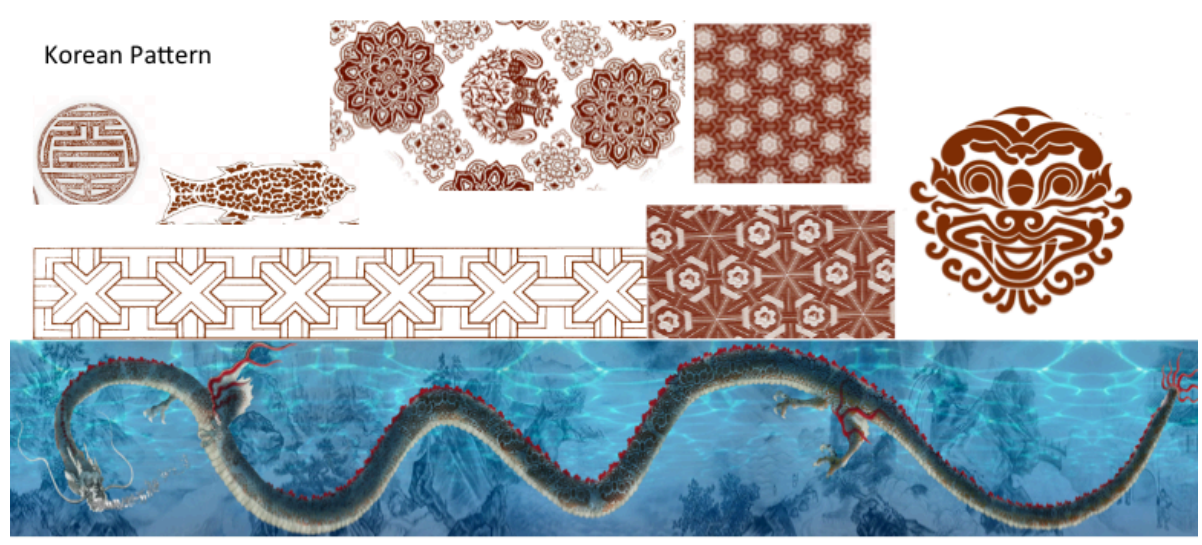

Figure 8.5 Dragon with Korean pattern

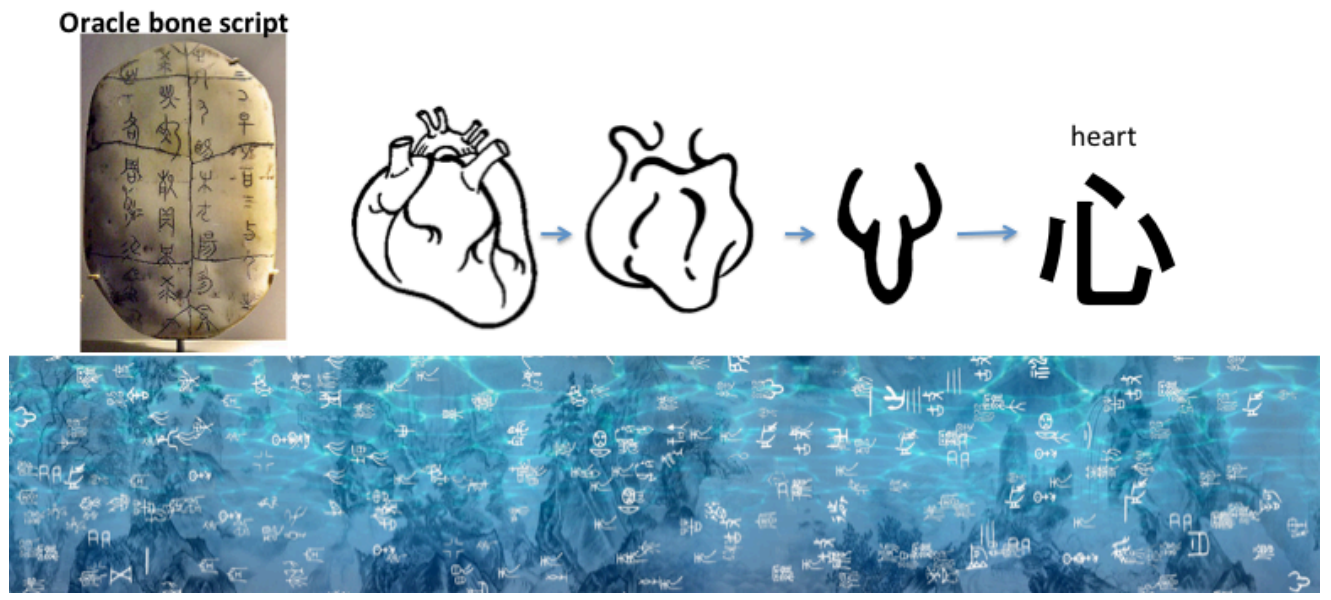

Figure 8.6 Under water Sansui with Oracle bone script animation 